Evaluación energética de la península de Yucatán: Vías para un sistema energético limpio y sustentable

Riccardo Bracho, Francisco Flores-Espino, Jonathan Morgenstein, Alexandra Aznar, Ricardo Castillo, y Edward Settle

Laboratorio Nacional de Energía Renovable 


\title{
Evaluación energética de la península de Yucatán: Vías para un sistema energético limpio y sustentable
}

\author{
Riccardo Bracho, Francisco Flores-Espino, Jonathan \\ Morgenstein, Alexandra Aznar, Ricardo Castillo, y Edward \\ Settle
}

Laboratorio Nacional de Energía Renovable

\section{Cita sugerida}

Bracho, Ricardo, Francisco Flores-Espino, Jonathan Morgenstein, Alexandra Aznar, Ricardo Castillo, y Edward Settle. 2021. Evaluación energética de la península de Yucatán: Vías para un sistema energético limpio y sustentable. Golden, CO: Laboratorio Nacional de Energía Renovable. NREL/TP-7A40-81142. www.nrel.gov/docs/fy21osti/81142.pdf.

EI Laboratorio Nacional de Energía Renovable (NREL) es un laboratorio nacional de la Oficina de Eficiencia Energética y Energía Renovable del Departamento de Energía de EE. UU.

Operando por Alliance for Sustainable Energy, LLC

Este informe está disponible sin consto en el Laboratorio Nacional de Energía Renovable en www.nrel.gov/publications.
Informe técnico

NREL/TP-7A40-81142

Septiembre de 2021

Laboratorio Nacional de Energía Renovable 15013 Denver West Parkway Golden, CO 80401

303-275-3000 • www.nrel.gov 


\begin{abstract}
AVISO
Este trabajo fue realizado por el Laboratorio Nacional de Energía Renovable, operado por Alliance for Sustainable Energy, LLC, para el Departamento de Energía (DOE, por sus siglas en inglés) de los Estados Unidos en virtud del Contrato N. ${ }^{\circ}$ DE-AC36- 08GO28308. Fondos proporcionada por Children's Investment Fund Foundation en el marco de la 21st Century Power Partnership bajo el ACT-15-00008. Las opiniones expresadas en el artículo no representan necesariamente los puntos de vista del DOE o del Gobierno de los Estados Unidos o de cualquier agencia del mismo.

Este informe está disponible sin costo en el Laboratorio Nacional de Energía Renovable (NREL) en www.nrel.gov/publications.

Los informes del Departamento de Energía (DOE) de los Estados Unidos producidos después de 1991 y un número en aumento de documentos anteriores a 1991 están disponibles de manera gratuita a través de www.OSTI.gov.
\end{abstract}

Foto de portada de iStock 183885566.

EI NREL imprime en papel con contenido reciclado. 


\section{Agradecimientos}

Los autores desean agradecer la colaboración de las siguientes personas: Courtney Beale y Giovanna Cabrera del Consulado General de EE. UU. en Mérida; Ramón Escobar y Andrew Winkelman de la Oficina de Energía del Departamento de Estado de los Estados Unidos en la Embajada de los Estados Unidos en la Ciudad de México; Juan Carlos, Vega Milke y Mirelle de Fátima Segovia Martín de la Secretaría de Fomento Económico y del Trabajo de Yucatán; Efraín Villanueva Arcos y Fermín Vázquez Ara de la Secretaría de Ecología y Medio Ambiente y de la Secretaría de Desarrollo Económico de Quintana Roo; Roberto de Jesús Hernández y José María Cú Cañetas del Ministerio de Desarrollo de Energía Sustentable del Estado de Campeche y de la Agencia de Energía del Estado de Campeche, respectivamente. 


\section{Lista de acrónimos}

21CPP

CEIA

CFE

CRE

CONCANACO

CONUEE

DG

ESA

FIPATERM

GCR

GCR ORI

GCR PEN

LCOE

LMP

GNL

NREL

PACC-BEA

PPA

PV

SENER

SIN

SLC $21^{\text {st }}$ Century Power Partnership

Clean Energy Investment Accelerator

Comisión Federal de Electricidad

Comisión Reguladora de Energía

Confederación de Cámaras Nacionales de Comercio de México

Comisión Nacional para el Uso Eficiente de la Energía

Generación distribuida

Escárcega

Fondo para la Eficiencia Energética

Área de control regional

Centro de Control Regional de Oriente

Centro Regional de Control Peninsular

Costo nivelado de la electricidad

Precio marginal local

Gas natural licuado

Laboratorio Nacional de Energía Renovable

Acelerador de Eficiencia Energética en Edificaciones

Acuerdo de compra de energía

Fotovoltaico

Ministerio de Energía

Sistema interconectado de electricidad

Santa Lucía 


\section{Resumen ejecutivo}

La región peninsular de Yucatán («Península») es la más oriental de México y comprende tres estados: Campeche, Yucatán y Quintana Roo. La Península cuenta con abundantes recursos naturales, numerosas zonas arqueológicas y protegidas, un alto crecimiento económico, uno de los mejores destinos turísticos de México y un sector energético único caracterizado por:

- La generación de energía está dominada por los combustibles fósiles convencionales, pero es rica en potencial de energía renovable: El gas natural y las centrales térmicas convencionales proporcionan actualmente la mayor parte de la electricidad de la Península. Sin embargo, la Península tiene un excelente potencial técnico solar y eólico. Aunque las energías renovables representan solo el $12.5 \%$ de la capacidad de generación actual, actualmente se están desarrollando hasta $1500 \mathrm{MW}$ de nuevos proyectos solares y eólicos (Oficina de Energía de Yucatán).

- Aumento de la demanda de electricidad que supera las expectativas: Entre 2017-2019, la Península experimentó un aumento constante del consumo bruto anual de electricidad y de la demanda horaria máxima que superó las previsiones del Gobierno. Aunque la pandemia de COVID19 interrumpió esa tendencia en 2020, se espera que la demanda repunte debido al aumento de la expansión económica, lo que refleja la necesidad urgente de resolver las limitaciones de suministro existentes (Ministerio de Economía).

- Problemas de suministro de gas y confiabilidad del sistema, que contribuyen a su elevado costo: Debido a la escasez de suministro de gas natural y a la insuficiente capacidad de transmisión (que crea congestión) entre la Península y el resto del país, la electricidad es cara y poco confiable; a menudo los generadores locales recurren a alternativas caras y contaminantes (por ejemplo, el combustóleo) o al gas natural cuando se enfrentan a la escasez (Monitor de Mercado). A medida que crecen las necesidades energéticas de la Península, no hay ninguna vía aparente a corto plazo y rentable para aumentar el suministro y la calidad del gas natural hasta los niveles necesarios para satisfacer plenamente la demanda. Es probable que las ampliaciones previstas de los gasoductos no satisfagan las necesidades de la Península a corto plazo. Las importaciones de gas natural licuado (GNL) pueden remediar la escasez, pero el precio del GNL es considerablemente más alto que el del gas natural por gasoducto. Aunque el refuerzo y la ampliación de la red de transmisión son necesarios para la región, los ajustes operativos también pueden aportar beneficios al sistema existente. Esta confluencia de retos hace que Yucatán se enfrente a precios de electricidad más altos y a cortes del servicio más frecuentes que otras regiones de México.

A la luz de estos retos y oportunidades, los tres estados de la Península están elaborando planes energéticos coordinados y trabajando juntos para transformar su sector energético aumentando el despliegue de tecnologías renovables de gran escala y distribuidas, aplicando programas de eficiencia energética y desarrollando soluciones de transporte sustentable. Este informe ofrece ejemplos de posibles acciones dirigidas a aumentar el despliegue de las energías renovables y la eficiencia energética en la región, entre ellas:

- Subastas regionales de energía limpia basadas en zonas competitivas de energía renovable

- Programas de eficiencia energética estructurados para edificaciones gubernamentales y pequeñas empresas

- Agregación del consumo de los edificios gubernamentales como usuarios calificados y diseño de mecanismos de adquisición

- Agregación de la demanda para sistemas fotovoltaicos (PV) de generación distribuida (DG)

- Uso de los ejidos (agricultura comunitaria) para acoger el despliegue de energías renovables 
- Despliegue de vehículos eléctricos para apoyar el transporte urbano sustentable.

Se espera que la implementación de algunas de estas opciones haga que la región peninsular sea más autosuficiente, reduzca los precios de la energía, aumente la confiabilidad del sistema y libere el suministro de gas natural para otros usos, a la vez que atraiga inversiones del sector privado y reduzca los precios de la electricidad.

Este informe comienza con una visión general de la situación del sector eléctrico en la península de Yucatán, incluyendo los principales desafíos, seguido de soluciones de políticas y programas que allanan el camino para un sector eléctrico más limpio y sustentable en la península de Yucatán. Este trabajo pretende proporcionar información a los estados de la península de Yucatán para la priorización y futura asistencia técnica del programa 21 st Century Power Partnership (21CPP) en México. La colaboración podría incluir la recopilación de datos, el desarrollo de capacidades, la elaboración de modelos y análisis, y el establecimiento de programas y políticas para ayudar a los estados y a la región en general a utilizar mejor sus recursos para satisfacer las necesidades de electricidad, al tiempo que se aplican medidas de eficiencia energética para lograr un sistema más sustentable, limpio, asequible y confiable. 


\section{Índice}

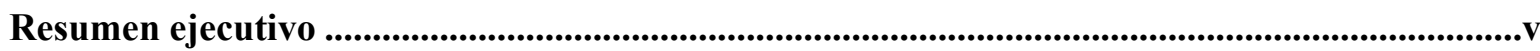

1 Evaluación del sector eléctrico de la Península de Yucatán .................................................1

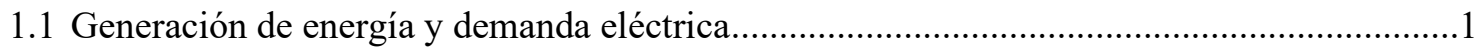

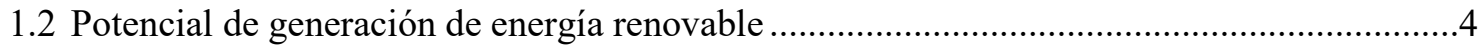

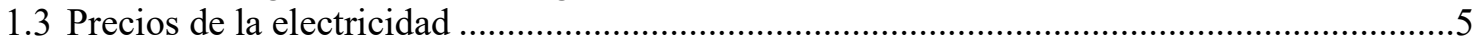

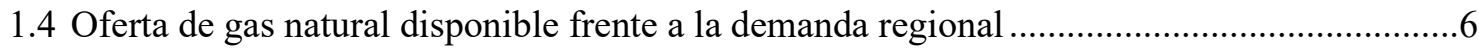

1.4.1 Medidas para hacer frente a las limitaciones del gas ......................................... 9

1.5 Interconexión regional y oportunidades de expansión de la red.........................................10

2 Rutas para la transformación del sector eléctrico en la Península de Yucatán.....................11

2.1 Oportunidades de energía renovable con proyectos de gran escala .....................................12

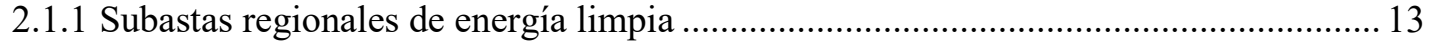

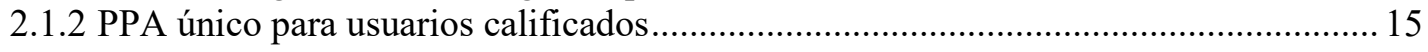

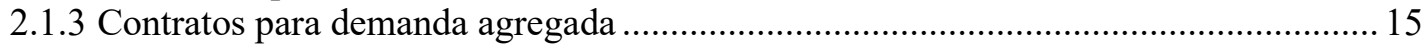

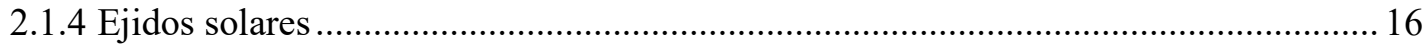

2.2 DG

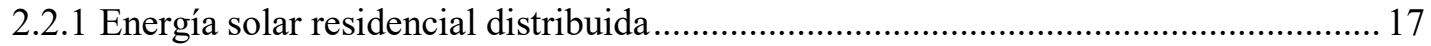

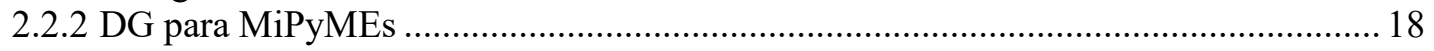

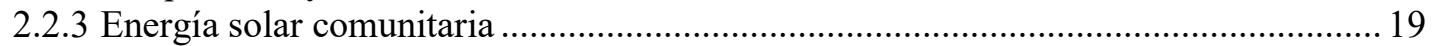

2.2.4 DG Opciones de política pública para los Estados de la Península .............................. 19

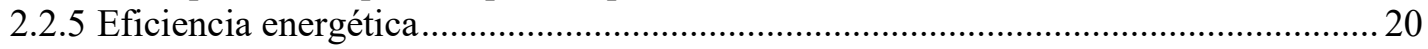

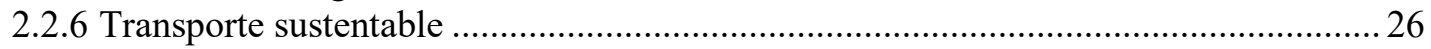

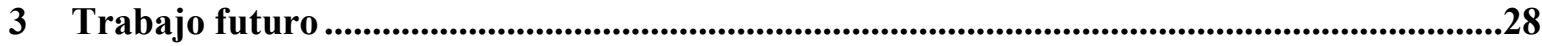

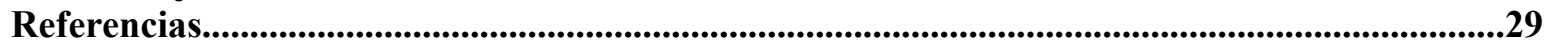

Anexo A: Mejores prácticas y soluciones de eficiencia energética por tipo de sistema ..............32

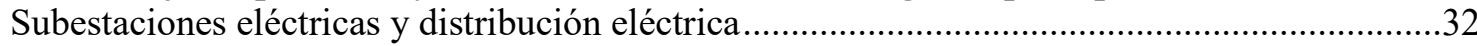

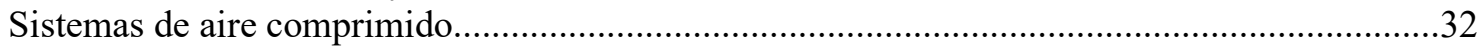

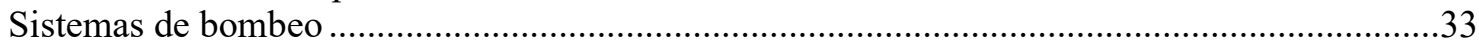

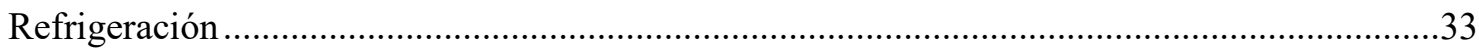

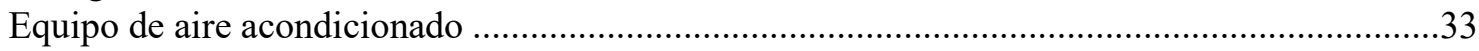

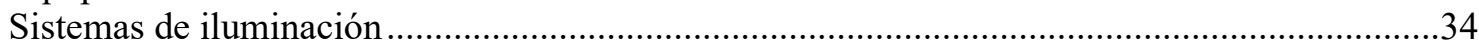

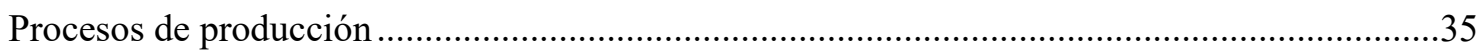

Anexo B: Panorama de la generación de energía en México .................................................36

Confiabilidad con una mayor penetración de las tecnologías renovables variables....................40 


\section{Lista de figuras}

Figura 1. La capacidad de generación de energía por tecnología muestra un $78 \%$ de combustibles fósiles y

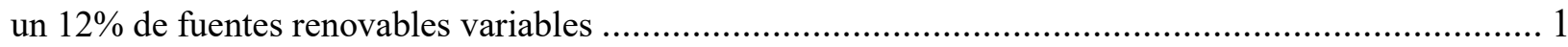

Figura 2. Desglose estatal de la capacidad de generación de energía por tecnología............................ 2

Figura 3. Consumo anual de electricidad y demanda máxima .................................................. 3

Figura 4. Precios marginales locales de la electricidad en 2018 por región de control ......................... 6

Figura 5. El gasoducto de Mayakan y las ampliaciones de Cuxtal .............................................. 8

Figura 6. El gasoducto de Mayakan antes de la ampliación de 2020 ......................................... 8

Figura 7. Proyectos de infraestructura propuestos para el gasoducto de Mayakan .............................. 9

Figura 8. Transmisión del GCR PEN e interconexión con el GCR ORI ........................................ 11

Figura 9. Resultados del análisis de la Zona de Energías Renovables de México............................... 13

Figura B-1. Capacidad anual de generación de energía limpia en México frente a la de combustibles

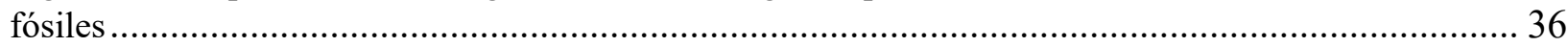

Figura B-2. Desglose de la capacidad de generación renovable anual de México................................. 37

Figura B-3. La generación anual de energía limpia en México frente a la generación basada en

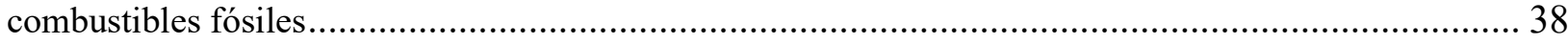

Figura B-4. Desglose de la generación anual de energía renovable en México................................... 38

Figura B-5. Factor de capacidad de generación eléctrica anual de México: energías limpias frente a

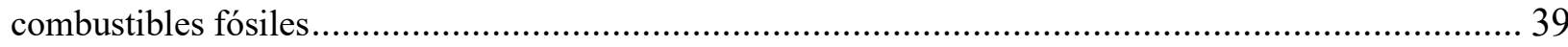

Figura B-6. Factores de capacidad estimados en México por tecnología renovable ............................. 40

\section{Lista de tablas}

Tabla 1. Potencial técnico eólico y solar (generación y capacidad) por Estado.........................4

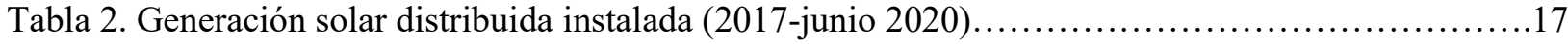

Tabla B-1. Consideraciones generales para el despliegue de tecnologías renovables en la Península......41 


\section{Evaluación del sector eléctrico de la Península de Yucatán}

\subsection{Generación de energía y demanda eléctrica}

La generación de energía para la Península se compone principalmente de turbinas de combustión alimentadas con gas natural y centrales térmicas, con una variación significativa entre los tres estados. Por ejemplo, el estado de Quintana Roo no tiene acceso a fuentes de gas natural y depende principalmente de la electricidad generada en el estado de Yucatán (más del $70 \%$ de la capacidad). Las figuras 1 y 2 muestran la combinación de capacidad de generación de energía por tecnología y por estado.

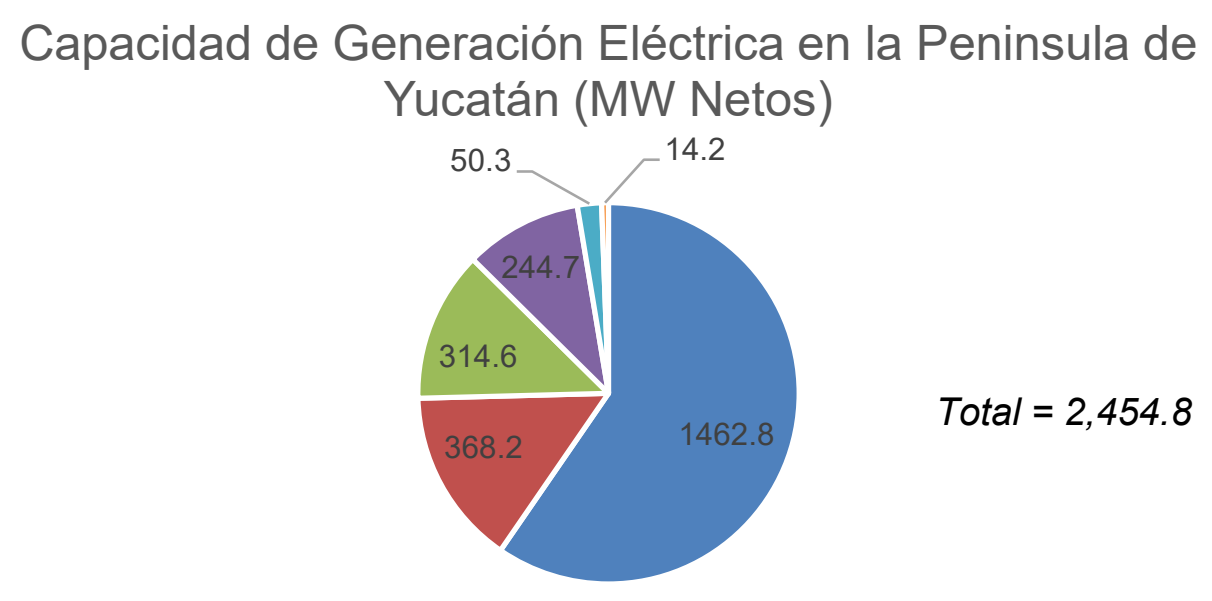

- Turbinas de Gas de Ciclo Combinado - Turbogas

- Térmica Convencional - Eólica

- Solar Fotovoltáica Combustión Interna

Figura 1. La capacidad de generación de energía por tecnología muestra un $78 \%$ de combustibles fósiles y un $12 \%$ de fuentes renovables variables

Fuente: NREL con datos del CENACE 


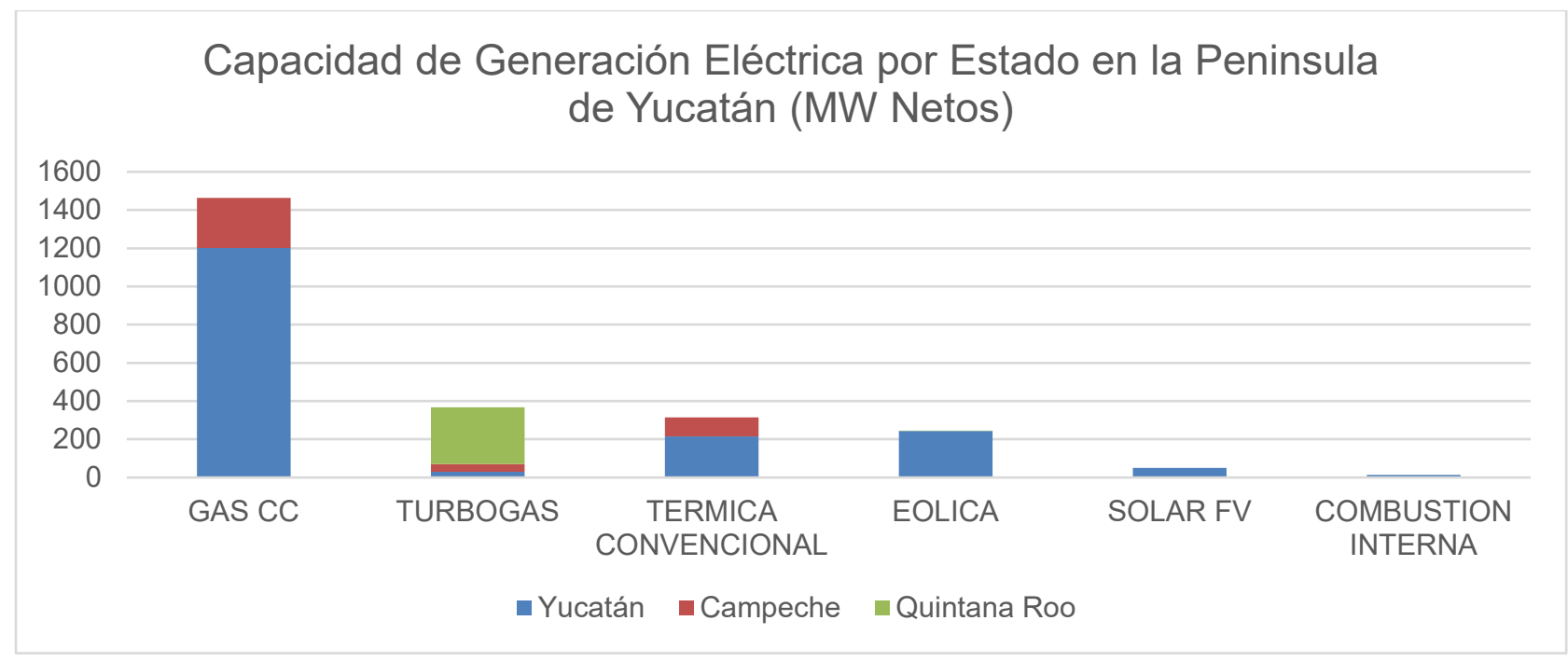

Figura 2. Desglose estatal de la capacidad de generación de energía por tecnología

Fuente: NREL con datos del CENACE

La red eléctrica interconectada de México está dividida en siete regiones de control operadas por el Centro Nacional de Control de Energía (CENACE). Campeche, Yucatán y Quintana Roo conforman el Centro de Control Regional Peninsular (GCR PEN) dentro del Sistema Interconectado de Electricidad (SIN) de México. El GCR PEN ha sufrido problemas de suministro eléctrico desde 2010, principalmente debido a las limitaciones operativas y al bajo suministro de gas a la región (MIM 2019). El insuficiente suministro de gas natural y su alto contenido en nitrógeno ${ }^{1}$ están limitando la capacidad operativa del parque de generación de la Península. Estos problemas han obligado a algunos generadores a convertir sus unidades a combustibles líquidos como el diésel y el combustóleo. Los generadores diseñados exclusivamente para funcionar con gas natural quedan expuestos a una alta indisponibilidad de combustible para la generación.

Aunque la capacidad de generación parece suficiente para cubrir las necesidades de electricidad de la península, los datos de generación y demanda muestran que el GCR PEN tiene periodos del año en los que el sistema está estresado debido a las contingencias locales y a la capacidad de generación disponible. El PRODESEN 2019-2033 muestra que la demanda de electricidad en el GCR PEN ha crecido de forma constante en los últimos años. En 2017, el consumo bruto de energía y la demanda máxima crecieron un $3.04 \%$ y un $3.37 \%$, respectivamente, respecto a 2016; en 2018, las mismas medidas crecieron un $3.9 \%$ y un 5.4\%, respectivamente, respecto al año anterior. Según el Monitor de Mercado, la demanda máxima de 2019 alcanzó los 2.254 MW y los 2.331 MW en el Mercado del Día y en el Mercado en Tiempo Real, lo que supone un crecimiento del $9.4 \%$ y del 13.1\% respecto a 2018, respectivamente. Mientras que en 2019 la capacidad local parecería suficiente para cubrir la demanda máxima del mercado diario y del mercado en tiempo real, en realidad, esta capacidad no se considera suficiente cuando se toman en cuenta los márgenes de reserva, la generación despachable y las contingencias del sistema local.

\footnotetext{
${ }^{1}$ PEMEX suministra gas natural a la Península, y gran parte de él contiene concentraciones relativamente altas de gas nitrógeno. El gas nitrógeno resulta de su inyección en campos petrolíferos envejecidos para intentar aumentar la producción de petróleo. El contenido de nitrógeno del gas natural ha ido aumentando cada año hasta alcanzar el $21 \%$ en 2019. En 2020, el porcentaje medio de contenido de nitrógeno era entre $12 \%$ y 16\%. Desde la ampliación del gasoducto de Mayakan hasta una segunda instalación de PEMEX, el contenido de nitrógeno en el gas natural se redujo a alrededor del 8\% (Oficina de Energía del Estado de Yucatán).
} 
De acuerdo con los escenarios de planeación del PRODESEN 2019-2033 elaborados por la Secretaría de Energía de México, la tasa de crecimiento promedio anual del consumo eléctrico y de la demanda máxima en los escenarios del GCR PEN es de 3.2\% y 3.5\%, respectivamente. La figura 3 muestra la previsión de crecimiento del consumo bruto de electricidad y de la demanda horaria máxima. Estas tasas de crecimiento previstas parecen bajas si se comparan con las tasas de crecimiento observadas entre 2017 y 2019. En 2020, debido a la COVID-19, la carga en el PEN GCR, al igual que en el resto del SIN, fue menor de lo esperado y la capacidad fue suficiente, pero es probable que esto sea un efecto temporal de la pandemia. Es difícil predecir cuándo volverá la demanda normal a la península, ya que los distintos sectores económicos se ven afectados de forma diferente. Aun así, la tendencia histórica de alto crecimiento de la demanda pone en duda la exactitud de las cifras oficiales de planificación de la Secretaría de Energía (SENER) y refleja la necesidad urgente de inversión en transmisión, infraestructura de suministro de gas natural y mayor uso de tecnologías de generación alternativas.

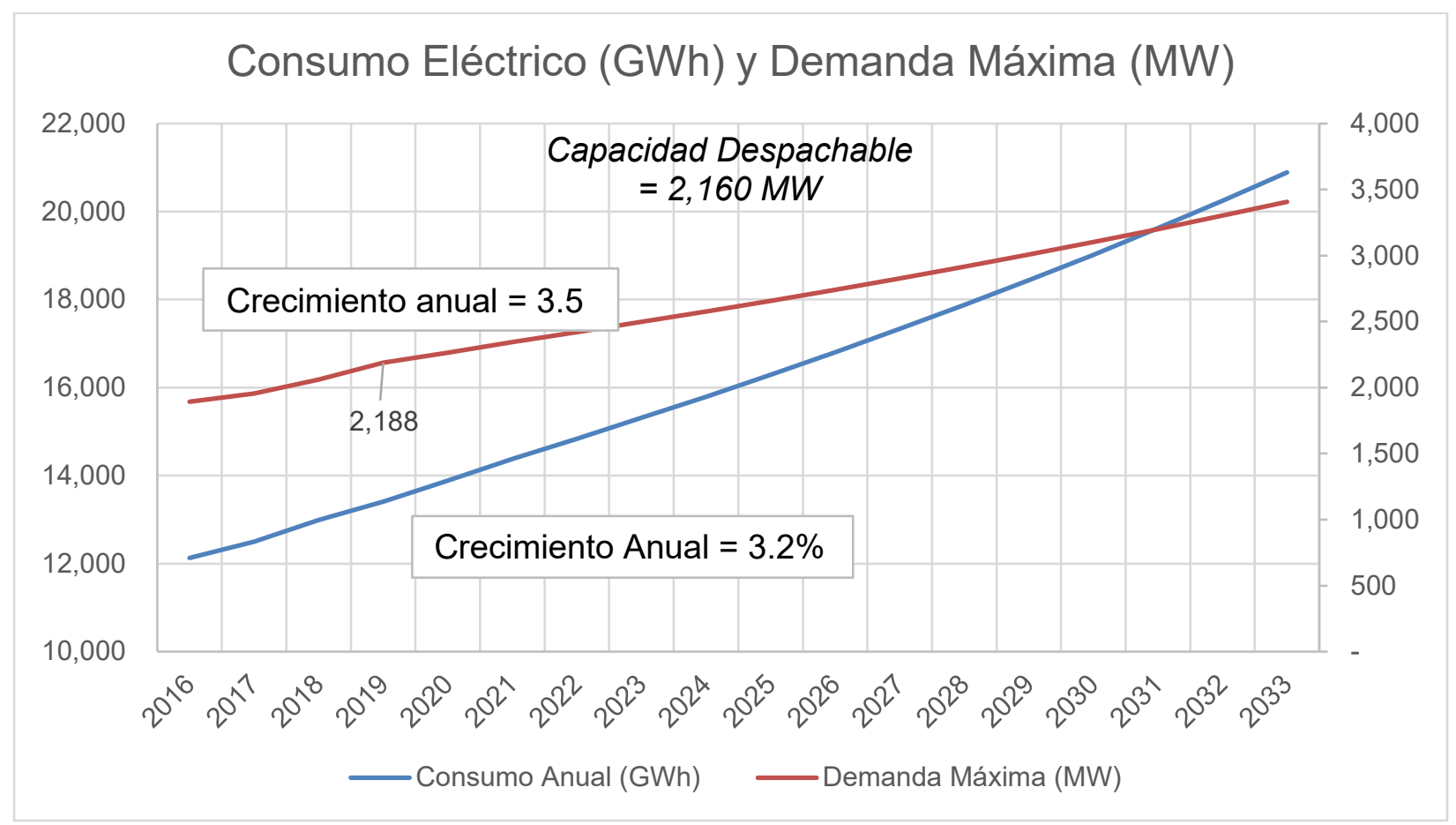

Figura 3. Consumo anual de electricidad y demanda máxima

Nota: El eje de la derecha muestra la demanda máxima y el de la izquierda la producción anual.

Fuente: NREL con datos de PRODESEN 2019-2033

Para satisfacer plenamente la demanda actual y creciente de la región peninsular, se anunciaron recientemente dos nuevas plantas de la Comisión Federal de Electricidad (CFE) con tecnología de turbinas de gas de ciclo combinado en 2020, entre ellas: (1) una nueva planta en Yucatán (Mérida IV) con una capacidad inicial de $500 \mathrm{MW}$, y (2) otra planta, la primera de su tipo, en el estado de Quintana Roo (Riviera Maya) con una capacidad de 752 MW (documentos de planificación de la CFE). Si se construyen las dos nuevas centrales de la CFE, la demanda de gas natural para la producción de electricidad aumentará de los $340 \mathrm{MMcf} / \mathrm{d}$ actuales a más de $540 \mathrm{MMcf} / \mathrm{d}$, lo que agravará el problema del bajo suministro y la baja calidad (alto contenido de nitrógeno) del gas en la región. Además de las incertidumbres sobre el suministro de gas natural, la disponibilidad de financiamiento y el impacto medioambiental y social, los estudios y requisitos podrían retrasar seriamente el desarrollo y la construcción de estos dos nuevos proyectos. 
Durante los últimos meses de 2020, parecía que la CFE estaba reconsiderando el proyecto de la Riviera Maya, y en su lugar proponía construir la segunda planta de energía en Valladolid, Yucatán, donde ya existe otra planta. Según la CFE, la infraestructura de transmisión es suficiente para enviar la nueva energía a Quintana Roo, pero probablemente necesitaría una serie de refuerzos e inversiones. También será necesario un estudio para conocer los efectos sobre los precios y la congestión del transporte al trasladar esta central a Valladolid. La cancelación de la central eléctrica de la Riviera Maya repercutiría en todos los sectores energéticos y no energéticos de Quintana Roo. En concreto, la planta de la Riviera Maya habría obligado a ampliar el gasoducto Mayakan a través del proyecto Cuxtal II (véase la sección de gas disponible), que podría suministrar gas natural al amplísimo sector turístico y permitir a Quintana Roo aprovechar las oportunidades adicionales del sector industrial.

\subsection{Potencial de generación de energía renovable}

Los tres estados de la Península de Yucatán son ricos en fuentes de energía renovable, especialmente en energía solar. La tabla 1 muestra el potencial técnico ${ }^{2},{ }^{3}$ de la energía solar y eólica en la región por capacidad y generación anual, teniendo en cuenta las exclusiones terrestres necesarias de la región y la distancia a la transmisión que la CFE, la empresa nacional de servicios públicos considera en sus propios cálculos de potencial.

Tabla 1. Potencial técnico eólico y solar (generación y capacidad) por Estado

\begin{tabular}{|c|c|c|c|c|}
\hline & & Campeche & Yucatán & Quintana Roo \\
\hline \multirow{3}{*}{ SOLAR } & Superficie urbanizable (Km2) & 20208.39 & 21050.56 & 4667.50 \\
\hline & Capacidad (MW) & 727502.05 & 757819.99 & 168029.83 \\
\hline & Generación Anual (GWh) & 1313849.08 & 1359777.40 & 299757.01 \\
\hline \multirow{3}{*}{ EÓLICA } & Superficie urbanizable $(\mathrm{Km} 2)$ & 533.08 & 2041.90 & 678.46 \\
\hline & Capacidad (MW) & 1599.26 & 6125.71 & 2035.42 \\
\hline & Generación Anual (GWh) & 3767.35 & 14802.23 & 4796.89 \\
\hline
\end{tabular}

Fuente: NREL ${ }^{4}$

La capacidad eólica y solar representa actualmente 295 MW o el 12.1 \% de la capacidad eléctrica total de la región. El potencial técnico calculado para el desarrollo solar y eólico en la región es de 1653.351 MW y 9760 MW, respectivamente. Entre 1200 y 1500 MW de nueva capacidad eólica y solar se encuentran actualmente en distintas fases de desarrollo.

Al final del tercer trimestre de 2020, la capacidad renovable de energía a granel proveniente de la energía eólica y solar ascendía a 295 MW o el 12.1\% de la capacidad total en la región (Oficina de Energía de Yucatán) La información de los estados y de las asociaciones de energía renovable de México indican que

\footnotetext{
${ }^{2}$ El potencial técnico no tiene en cuenta el contexto político y normativo que, a su vez, influye en el potencial económico y de mercado.

${ }^{3} \mathrm{Al}$ evaluar el potencial técnico de la generación eólica y solar, es importante conocer el recurso natural, como la velocidad del viento a distintas alturas y la irradiación solar, la tecnología específica y el tipo de instalación elegida.

${ }^{4}$ Potencial técnico calculado mediante el Explorador de Datos de Energías Renovables del Laboratorio Nacional de Energías Renovables (NREL), https://www.re-explorer.org/.
} 
entre 1200 y 1500 MW de nuevas plantas de energía solar y eólica están en diversas etapas de desarrollo (Oficina de Energía de Yucatán)

Además de la eólica y la solar, la región peninsular cuenta con otros recursos renovables que pueden ofrecer generación de electricidad despachable, como la biomasa, la conversión de residuos en energía y otras tecnologías. En el Anexo B se ofrece una evaluación de las opciones.

\subsection{Precios de la electricidad}

La Península de Yucatán mantiene algunas de las tarifas eléctricas más altas del Sistema Interconectado Nacional de Electricidad (SIN) en México. La Figura 4 muestra los precios marginales locales (PML) promedio de 2018 para cada una de las siete Áreas de Control Regional (GCR) del SIN. El LMP promedio de 2018 para el GCR PEN de MXP \$2292.34/MWh (bastante más de \$100/MWh al tipo de cambio de 2018) fue el más alto del sistema y 39\% más alto que su vecino, el GCR ORI. En 2019, el LMP medio del año de todos los centros de control regionales del sistema interconectado nacional disfrutó de reducciones debido al aumento de la generación disponible de las nuevas centrales eléctricas y a las reducciones del costo del gas natural. Las regiones de control con mayores reducciones de precios fueron los tres centros regionales del norte del país (entre el $-28 \%$ y el $-42 \%$ ), mientras que la menor reducción de precios se observó en el GCR PEN con solo una reducción media del -4.8\% (MIM 2019).

Hay varias razones por las que Yucatán se enfrenta con los precios más altos del sistema eléctrico y con cortes de servicio más frecuentes que otras regiones. Por un lado, el GCR PEN tiene poca integración con el resto del SIN, ya que tiene un único punto de conexión con el GCR ORI, que utiliza un único corredor de transmisión (MIM 2019). La ampliación de la red de transmisión no ha seguido el elevado crecimiento de la demanda y la oferta en la región. Como resultado, la red sufre muchas horas de saturación que aumentan los precios de la electricidad. Un análisis de 2019 sobre los costos de generación, la inversión y los precios en el sector eléctrico mexicano, encontró que en general, los altos precios en México están altamente correlacionados con la congestión de la transmisión en el SIN, y no es el resultado de un diseño de mercado competitivo ineficiente. (Enriquez, Rosellón et al. 2019). Además de las limitaciones de transporte, el suministro de gas natural a la península no es suficiente para cubrir la totalidad de la generación eléctrica, lo que provoca la indisponibilidad para la generación y que varias de las centrales térmicas recurran al uso de combustibles más caros y contaminantes como el combustóleo y el diésel. Por último, las tecnologías renovables solar y eólica, que son las que proporcionan los precios marginales más bajos cuando el recurso renovable es más fuerte, aportan un bajo porcentaje de la generación de electricidad en la zona. A medida que la generación de energía eólica y solar aumente como porcentaje de la generación total en la península, los LMP tenderán a bajar (NREL). 


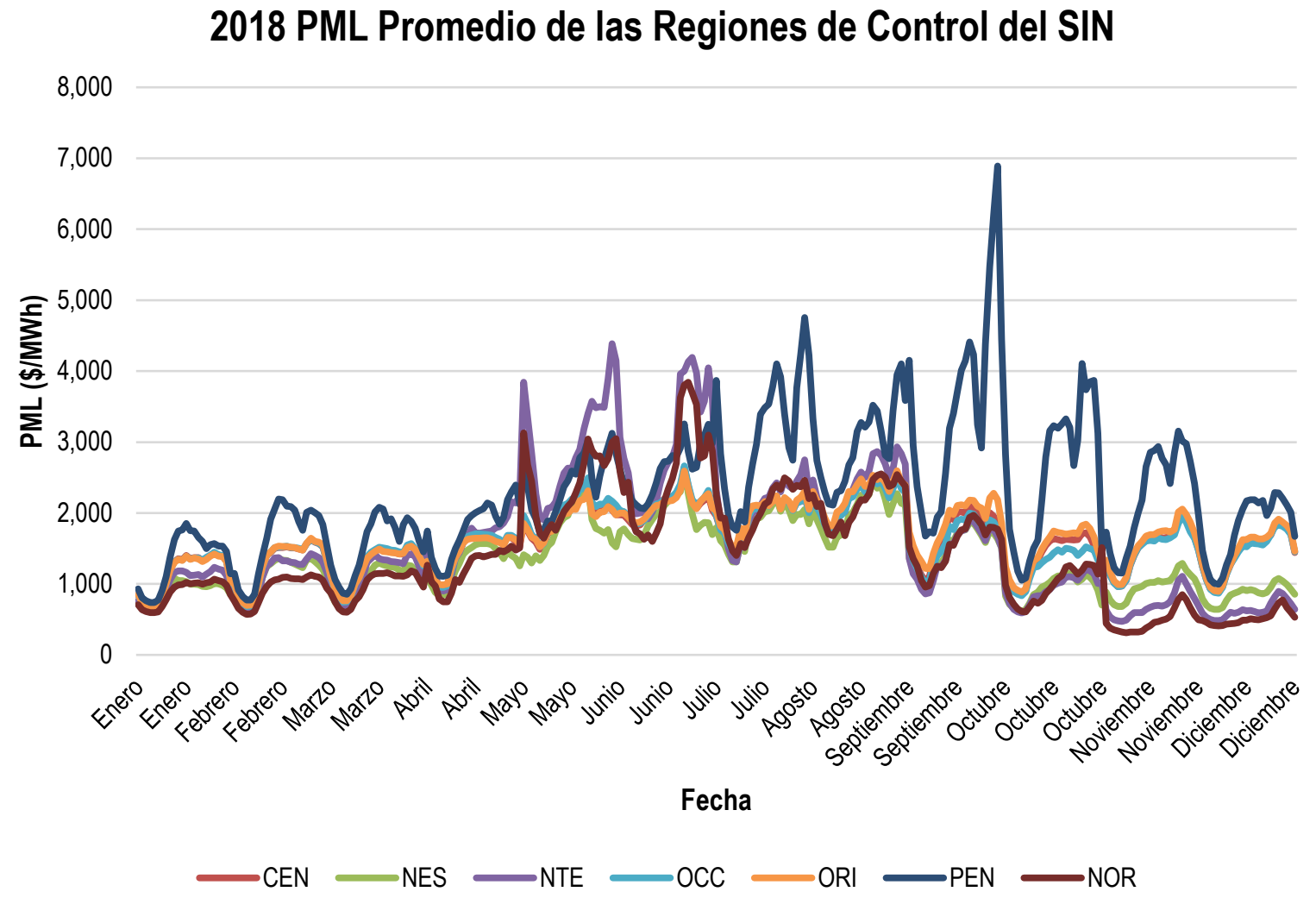

Figura 4. Precios marginales locales de la electricidad en 2018 por región de control

Fuente: Monitor de Mercado con datos del CENACE

En 2018, los precios medios de la electricidad en la península fueron los más altos del SIN y

un $39 \%$ superiores a los de su región vecina GCR ORI. Las principales causas son el bajo

suministro de gas natural, que obliga a la mayor parte de la matriz de generación,

principalmente fósil, a utilizar combustóleo y diésel, y la indisponibilidad del sistema, la

congestión de la transmisión y un pequeño porcentaje de generación renovable

\subsection{Oferta de gas natural disponible frente a la demanda regional}

El gas natural es el principal combustible necesario para el funcionamiento de las centrales eléctricas instaladas en esta región. La escasez de gas natural hace que la región se enfrente a un déficit para cubrir sus necesidades de generación de energía y, posteriormente, de consumo industrial, comercial y residencial. Por esta razón, depende de las importaciones de electricidad a través de su único corredor de transmisión desde el GCR ORI (MIM 2019). Incluso con los actuales y futuros proyectos de infraestructura de gas previstos o potenciales para la región, no se espera que el problema se resuelva hasta dentro de varios años.

La región sufre un déficit de suministro de gas natural y de capacidad de transporte suficiente para satisfacer las necesidades regionales, incluso si el gas estuviera disponible. La CFE de la región tiene unas necesidades actuales de $340 \mathrm{MMcf} / \mathrm{d}$ para la generación de energía y necesitaría otros $200 \mathrm{MMcf} / \mathrm{d}$ si se construyen sus dos nuevas centrales de ciclo combinado. Según la CONCANACO, la demanda de gas 
natural en la región, sin las futuras centrales eléctricas de la CFE, es de aproximadamente $500 \mathrm{MMcf} / \mathrm{d}$, incluyendo $160 \mathrm{MMcf} / \mathrm{d}$ de requerimientos industriales y comerciales.

El gas natural se transporta a la Península a través del sistema de transporte de gas natural Mayakan Energy (Mayakan), propiedad de Engie. La Figura 5 muestra las Áreas de Control Regional en la red de México y muestra en el GCR PEN, el gasoducto Mayakan y sus dos ampliaciones originalmente propuestas, que podrían satisfacer plenamente las necesidades de la Península. En 2020, se completó una ampliación de 16 kilómetros (Cuxtal I) del gasoducto Mayakan. Con la ampliación, ahora el gasoducto de tipo telescópico de $796 \mathrm{~km}$ de longitud abarca cuatro estados, comenzando en Tabasco y continuando por Chiapas y Campeche hasta llegar a Valladolid, en Yucatán. Actualmente Mayakan no llega a Quintana Roo. La figura 6 muestra una imagen detallada del gasoducto Mayakan antes de la inauguración de la ampliación Cuxtal I en octubre de 2020. La capacidad de transporte de Mayakan es de $250 \mathrm{MMcf} / \mathrm{d}$. Antes de la finalización de la ampliación de $16 \mathrm{~km}$ de Cuxtal I, el gas disponible en la Península había disminuido a aproximadamente 60-80 MMcf/d de gas con alto contenido de nitrógeno (19-21\%). Como resultado de la finalización de Cuxtal I, la cantidad de gas transportado ha crecido hasta aproximadamente 120-140 MMcf/d, pero esta cifra sigue siendo inferior al 50\% de la capacidad total del gasoducto. El proyecto Cuxtal I también mejoró la calidad del gas, ya que el contenido de nitrógeno se redujo a alrededor del 8\%. Según los acuerdos de transporte, el 97\% o $243 \mathrm{MMcf} / \mathrm{d}$ de la capacidad es contratada por la CFE para entregar a los tres productores independientes de electricidad ubicados en Campeche, en Mérida y en Valladolid (Mayakan Energy). La falta de suministro ha obligado a varias plantas a utilizar diésel y combustóleo.

Las necesidades de gas natural para la generación de energía en la Península son actualmente de $340 \mathrm{MMcf} / \mathrm{d}$, y la demanda adicional de los sectores industrial, comercial y residencial aumenta esa cifra hasta los $500 \mathrm{MMcf} / \mathrm{d}$.

La capacidad de transporte de gas del gasoducto Mayakan es de solo 250 MMcf/d , y el $97 \%$ se contrata para la generación de energía, pero solo se dispone de 120-140 MMcf/d incluso después de que se completara la ampliación de Cuxtal I , lo que obliga a muchos generadores a reconvertirse y utilizar combustóleo o diésel. 


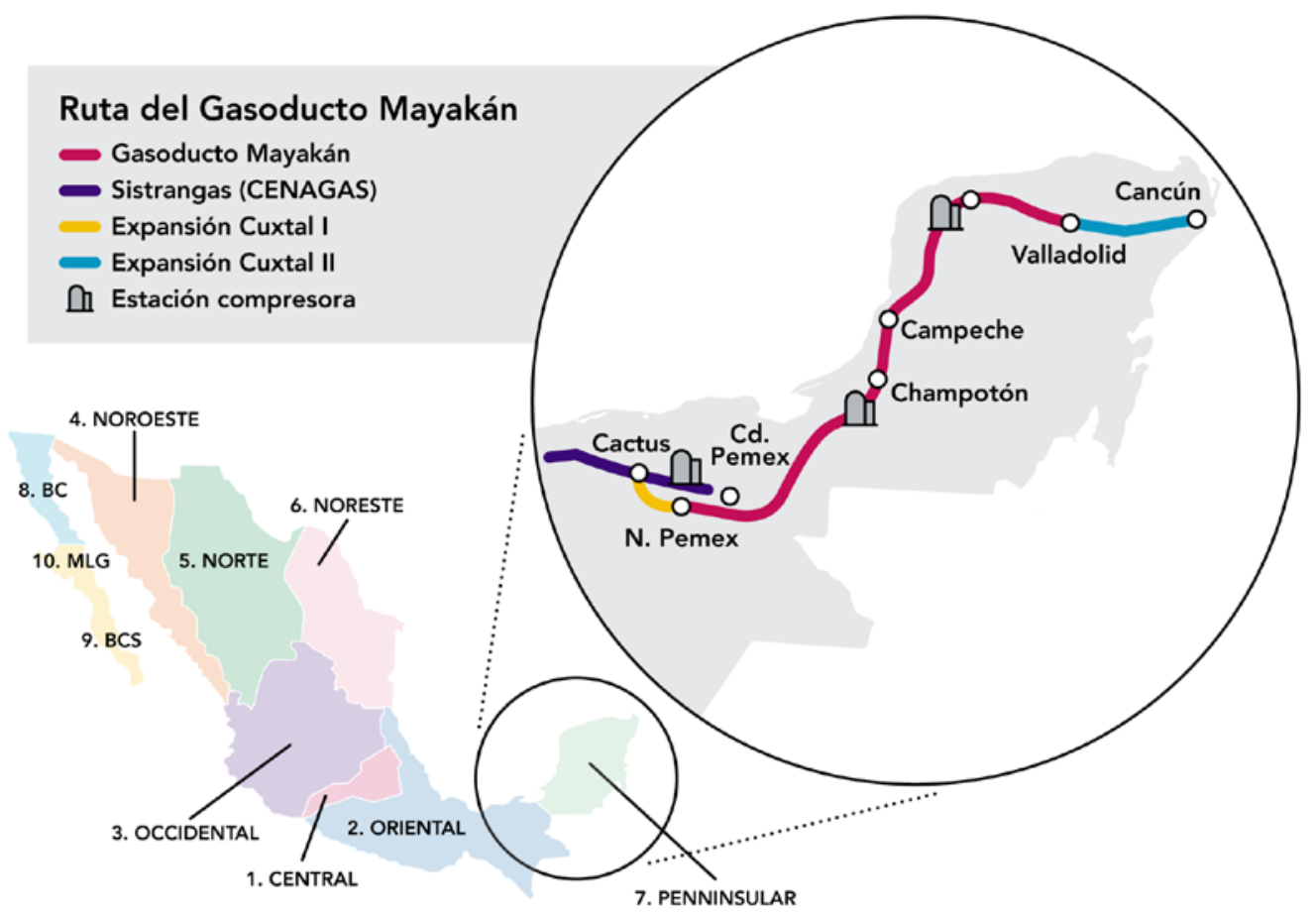

Figura 5. El gasoducto de Mayakan y las ampliaciones de Cuxtal

Fuente: NREL con información de PRODESEN 2019-2033 y gasoducto Cuxtal

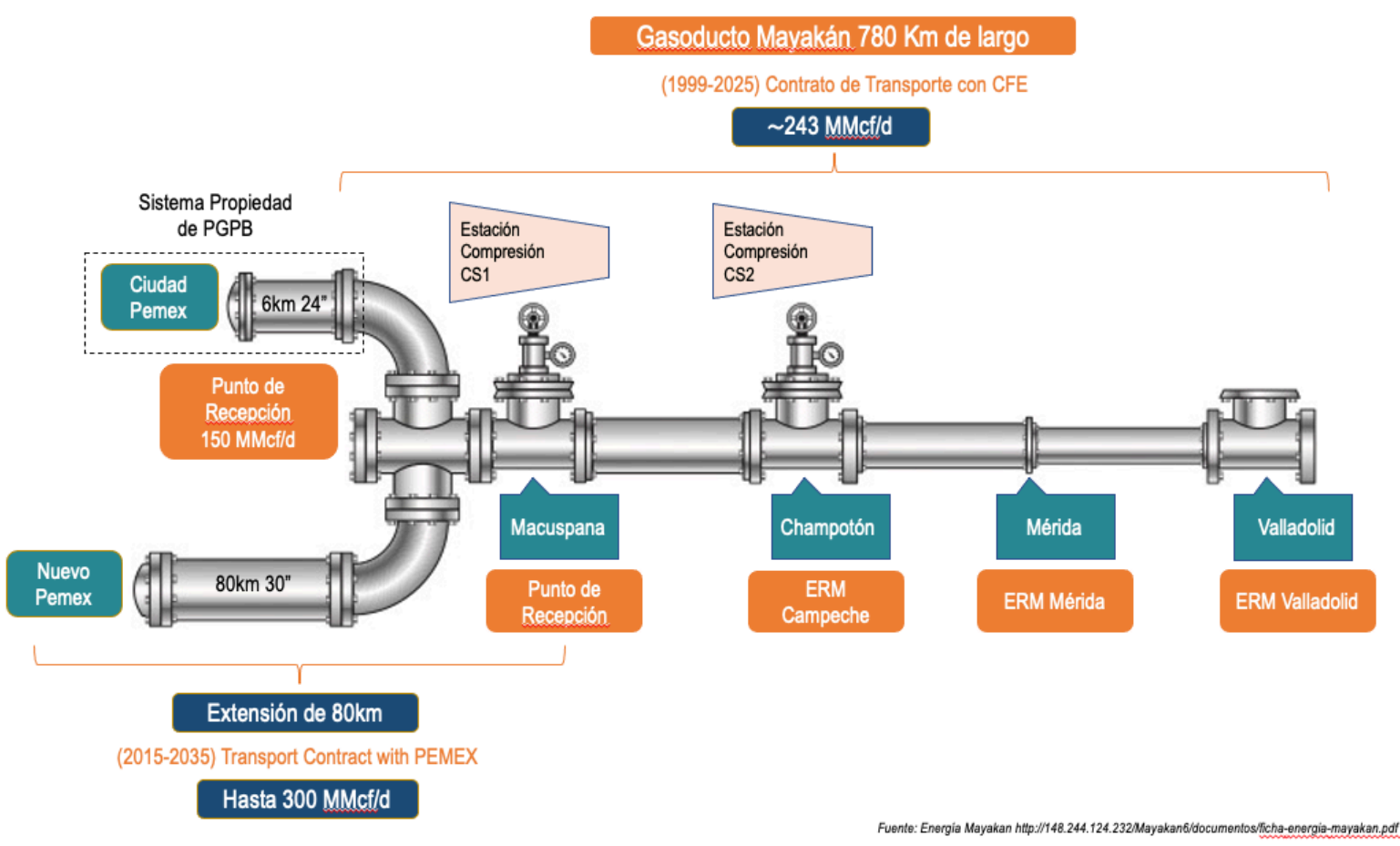

Figura 6. El gasoducto de Mayakan antes de la ampliación de $\mathbf{2 0 2 0}$

Fuente: Energía a Debate con información de la CFE. 


\subsubsection{Medidas para hacer frente a las limitaciones del gas}

Se están llevando a cabo algunas acciones, y otras están previstas o debatidas, para resolver la escasez de gas natural en el GCR. La primera fue la mejora de la infraestructura existente de Mayakan mediante la conexión del gasoducto de Mayakan al Sistema Nacional Integrado de Transporte y Almacenamiento de Gas Natural con la ampliación de Cuxtal I para permitir la utilización de toda su capacidad. El segundo proyecto de Mayakan (Cuxtal II) (no iniciado) incluye la construcción de una extensión de $160 \mathrm{~km}$ desde Valladolid, Yucatán, para llegar a Cancún, Quintana Roo (véase la figura 6). La finalización de Cuxtal I aumentó el gas en la región al permitir que Mayakan reciba gas de una segunda fuente de PEMEX, el centro de procesamiento de gas CACTUS. Cuxtal I también facilita un eventual uso de la capacidad total de suministro de Mayakan con el cambio de dirección de la estación de compresión de Cempoala para transportar gas natural a Cd. PEMEX, y aprovechando la entrada en operación del gasoducto submarino entre Tuxpan y el sur de Texas. El segundo proyecto de ampliación, Cuxtal II, no tiene fecha de inicio, y si la CFE cancela la central de la Riviera Maya, la ampliación de Cuxtal II también podría cancelarse.

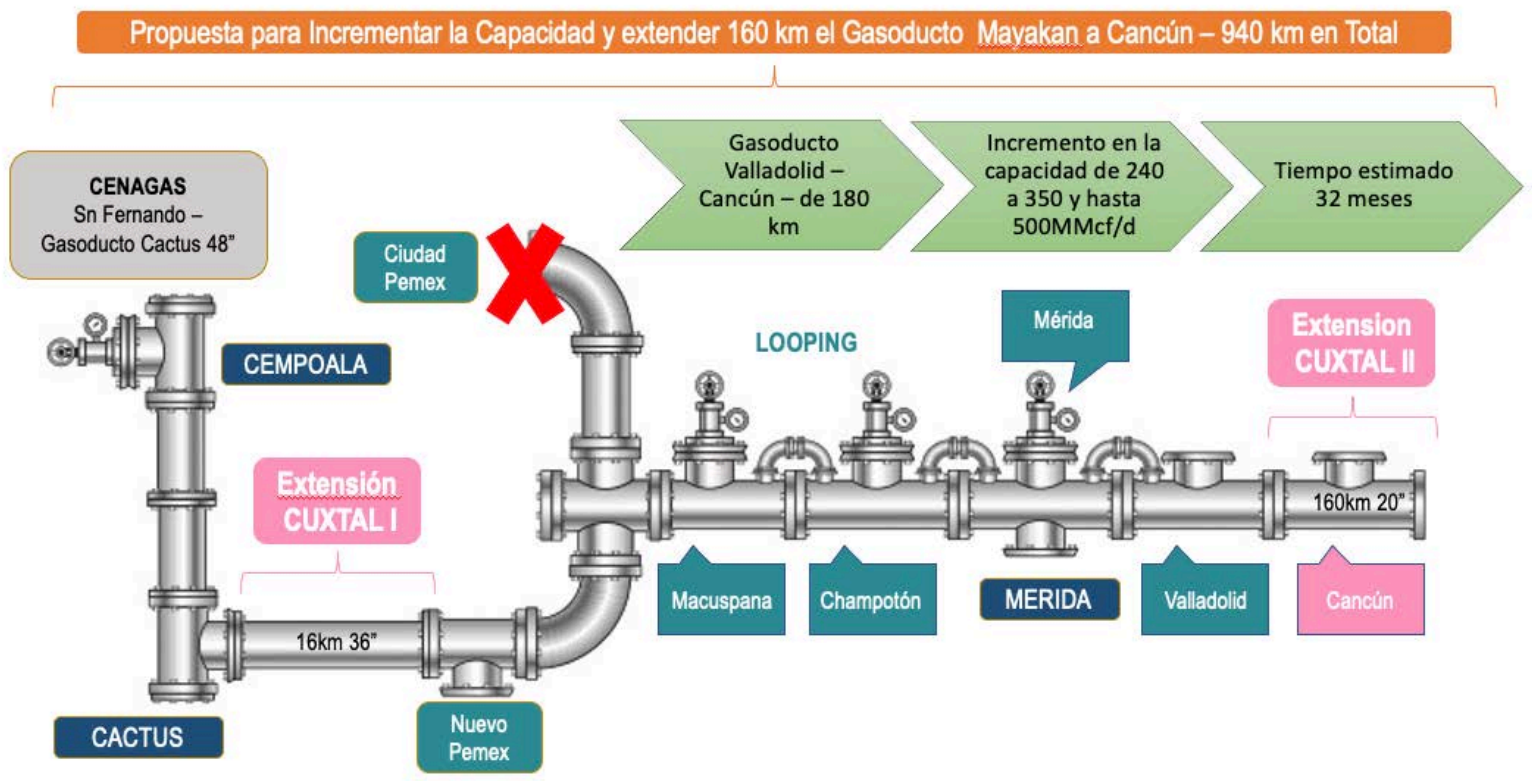

Figura 7. Proyectos de infraestructura propuestos para el gasoducto de Mayakan

Fuente: Energía a Debate con información de la CFE.

La segunda serie de alternativas que se analizan es el arrendamiento de buques cisterna (unidades flotantes de regasificación) para la compra consolidada de GNL en Estados Unidos y su suministro en toda la Península. Los estados de la península están analizando y trabajando para desarrollar este tipo de alternativas. De los proyectos que se estudian, el que está más avanzado es el de Campeche, denominado Suministro de Gas MEXITERM. El proyecto MEXITERM propone adquirir y transportar el GNL por barco hasta la costa de Campeche, el cual sería recibido por una unidad de regasificación y almacenamiento flotante ubicada aproximadamente a 20 o 30 kilómetros de la costa de Campeche. Si se construye, el proyecto comenzaría con una regasificación de $175 \mathrm{MMcf} / \mathrm{d}$ que se enviaría a través de un gasoducto de 20-30 kilómetros en alta mar hasta Campeche, donde el gas podría entrar en el gasoducto de Mayakan y/o podría distribuirse mediante el uso de camiones en tierra (Secretaría de Desarrollo Energético Sustentable del Estado de Campeche). Si se construye, los precios del gas de este proyecto serán más altos que los del gas natural transportado a través del gasoducto Mayakan. 
Hasta la fecha, el proyecto Cuxtal I se ha completado, pero no resolverá el problema del suministro de gas a la región. Por lo tanto, hasta que no se tomen medidas correctoras, existirá la perspectiva de escasez de gas natural y escasez de capacidad de generación de GCR PEN.

\subsection{Interconexión regional y oportunidades de expansión de la red}

Como se mencionó anteriormente, el GCR PEN está interconectado con el GCR ORI, y la interconexión sufre una saturación prácticamente todos los meses del año. Durante los meses de temperaturas más altas, cuando la demanda de electricidad aumenta en toda la región, el número de horas de saturación aumenta considerablemente. La figura 8 muestra la actual infraestructura de transmisión del GCR PEN y la interconexión con el GCR ORI. Las dos regiones están interconectadas a través de un corredor con cuatro líneas de transmisión: (i) dos a $230 \mathrm{kV}$, la primera entre las subestaciones Macuspana II y Santa Lucía (SLC), y la segunda entre las subestaciones Los Ríos y SLC; y (ii) dos líneas de $400 \mathrm{kV}$, ambas entre las subestaciones Tabasco y Escárcega (ESA). En la zona de carga de Chetumal, el GCR PEN está interconectado con el sistema eléctrico de Belice a través de un circuito simple de $115 \mathrm{kV}$, que se utiliza para las operaciones de exportación. (Informe del Monitor de Mercado del 2019 [MIM 2019]).

La transmisión entre los GCR ORI y PEN está normalmente limitada por un enlace o compuerta dentro del GCR PEN, definido por la interconexión entre las subestaciones SLC y ESA y entre la central de Tabasco y las subestaciones ESA, como se ha descrito anteriormente. La figura muestra el sistema de transmisión del GCR PEN y la puerta de entrada a la subestación de la ESA, que ha llegado a limitar los flujos entre el GCR ORI y el PEN. La región peninsular adolece de confiabilidad de suministro eléctrico en épocas de alta demanda y debido a la tensión del sistema. Como ejemplo, hay líneas de transmisión en ciertas áreas, incluyendo dos líneas de $400 \mathrm{kV}$ entre la ESA y Ticul II que comparten torres de transmisión, lo que las hace vulnerables a posibles dobles contingencias cuando su estructura física está en riesgo. Así ocurrió los días 5 y 22 de abril de 2019, cuando los incendios en los campos de azúcar situados bajo las torres impactaron en las líneas y provocaron cortes de servicio. Durante estas contingencias dobles, el sistema intentaría redirigir la energía a las líneas de $230 \mathrm{kV}$. El primer evento, el 5 de abril, se produjo en un momento de gran demanda de electricidad, y la mayor parte del GCR PEN quedó fuera de servicio durante casi 3 horas. Durante el segundo evento, el 22 de abril, las condiciones de funcionamiento fueron diferentes, y las líneas de $230 \mathrm{kV}$ pudieron reaccionar mejor al evento. La pérdida de potencia durante este tiempo duró apenas 17 minutos (MIM 2019). 


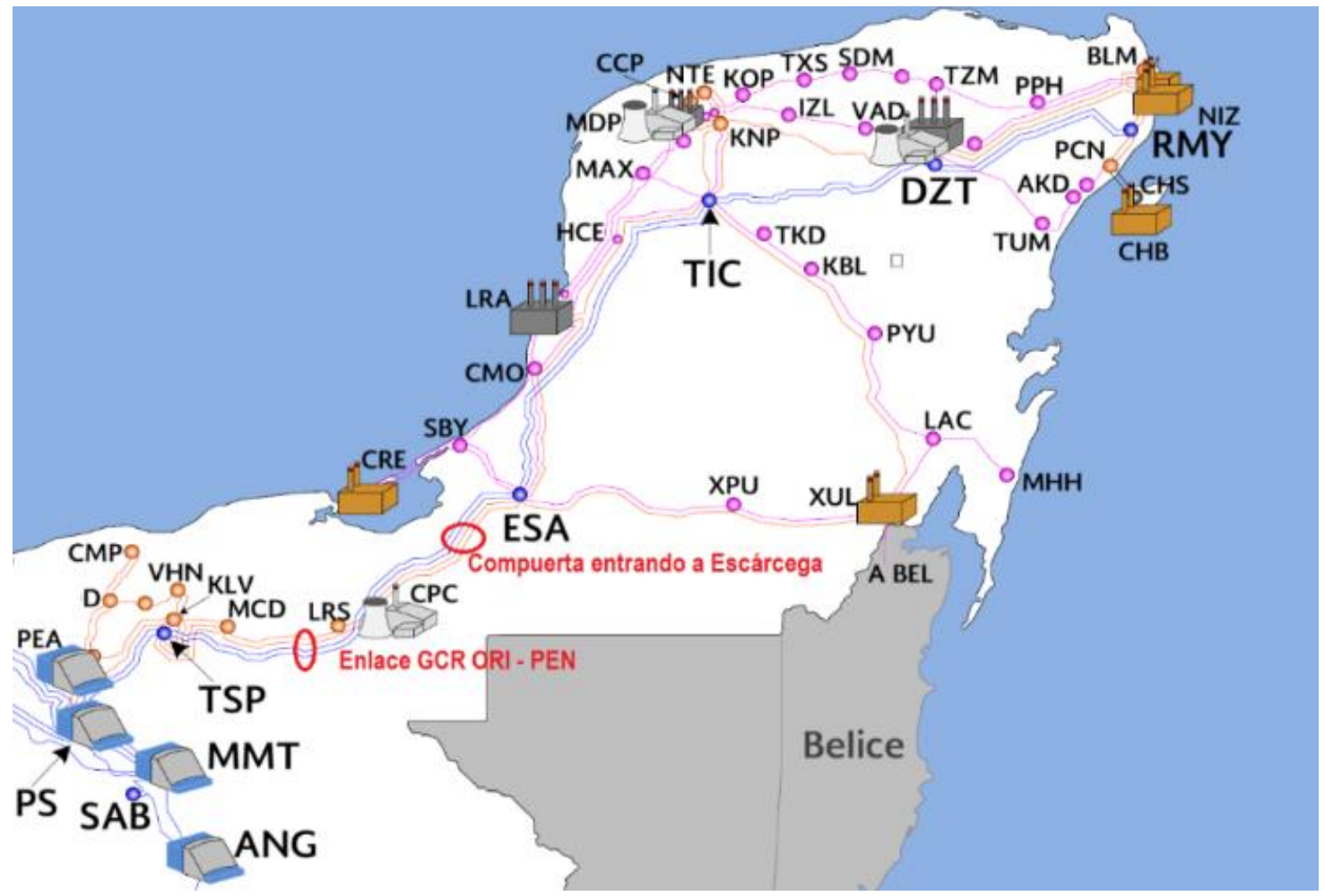

Figura 8. Transmisión del GCR PEN e interconexión con el GCR ORI

Nota: A efectos de este gráfico, se considera que la subestación eléctrica SLC y el generador CPC están geográficamente en el mismo punto

Fuente: MIM 2019

Aunque el refuerzo y la ampliación de la red de transmisión son necesarios para la región, especialmente con la construcción de dos nuevas centrales eléctricas de la CFE y otros proyectos renovables, los ajustes operativos también pueden aportar beneficios al sistema existente. Como ejemplo de ellos, el informe anual del MIM 2019 indica que entre abril y julio de 2018, la saturación de la conexión entre las dos RGC fue de 150 horas al mes de media. Durante el mismo periodo de 2019, la saturación aumentó un 65\%, alcanzando una media de 248 horas al mes. En agosto de 2019, el CENACE implementó cambios en las acciones de remediación, y para los meses de agosto y septiembre, la saturación se redujo a 88 horas, en comparación con las 366 horas durante los mismos dos meses de 2018.

\section{Rutas para la transformación del sector eléctrico en la Península de Yucatán}

En esta sección ${ }^{5}$, analizamos una serie de opciones políticas para que los estados de la península las apliquen individualmente y/o a nivel regional, con el fin de aumentar la sostenibilidad y la resiliencia del sector eléctrico, al tiempo que se reduzcan los precios de la energía. El estado de Quintana Roo es especialmente vulnerable: la mayor parte de su energía se importa de Yucatán. Se esperaba que el anuncio de la central eléctrica de la Riviera Maya supusiera un alivio muy necesario gracias a la generación local y a la posibilidad de disponer finalmente de gas natural a través del gasoducto de Mayakan. Si la CFE decide oficialmente construir la segunda planta en Yucatán, Quintana Roo tendrá que trabajar para

\footnotetext{
${ }^{5}$ Esta sección no abarca todas las soluciones potenciales anteriores, sino que sólo cubre las opciones de energías renovables y de eficiencia energética. Por lo tanto, las acciones que se están llevando a cabo en los mercados de gas natural, las oportunidades de expansión de la red, no se amplían aquí.
} 
desplegar grandes cantidades de energía renovable en todo el estado. Esta sección se divide en oportunidades de energía renovable para la energía con proyectos de gran escala, la generación distribuida (DG) y la eficiencia energética. La Península de Yucatán posee fuertes recursos solares y eólicos y ya ha demostrado su viabilidad con múltiples proyectos. Sin embargo, la Península también cuenta con otros recursos que deben ser explorados para la producción de energía sustentable y renovable. La economía agrícola extensiva puede ofrecer oportunidades para la producción de bioenergía (biomasa y biogás). Los desechos y las aguas residuales también pueden convertirse en energía útil. Merece la pena explorar otras tecnologías, como la oceánica y la hidroeléctrica. Por último, la Península también puede recurrir a la importación de soluciones sustentables y renovables en los casos en que la producción peninsular no se vea favorecida.

\subsection{Oportunidades de energía renovable con proyectos de gran escala}

Existen varias oportunidades para que los estados promuevan el despliegue continuado de la generación de energía renovable de gran escala (para México, se trata de aquellos con una capacidad superior a 500 $\mathrm{kW}$, mientras que en muchos países «de gran escala» suele referirse a proyectos con una capacidad de generación superior a varios MW). Entre las opciones que se analizan aquí están: el diseño de subastas regionales, las acciones para promover el desarrollo de proyectos de acuerdos de compra de energía (PPA) individuales y las soluciones para los programas de adquisición agregada. También hablamos de una nueva oportunidad en México para desarrollar ejidos solares. Esta última oportunidad puede funcionar para la generación de gran escala y para los proyectos de GD, dependiendo de la situación. Hay otras opciones de energía renovable a gran escala que no se analizan aquí, incluidos los promotores que deciden construir nuevas centrales eléctricas y participar como vendedores comerciales en el mercado mayorista debido al LMP históricamente alto en la región.

Una de las principales barreras a las que se enfrentan estas oportunidades son las limitaciones físicas de la actual infraestructura de red y los problemas de congestión en la región. Una red robusta requiere refuerzos, la ampliación de las líneas existentes y la construcción de líneas adicionales para alcanzar y conectar los mejores recursos renovables con los centros de carga.

En 2018, la SENER solicitó al NREL que analizara las Zonas Competitivas de Energías Renovables en México (véase Figura) en las que se construirían nuevas subestaciones para ampliar el sistema de transmisión para satisfacer mejor las demandas actuales y futuras de la red y para el diseño de futuras subastas de energías limpias a largo plazo. Los resultados de este análisis incluyeron dos zonas elegidas para la expansión de la transmisión en la Región Peninsular, una en Campeche y otra en Yucatán.

Bajo un proceso transparente con la participación de los gobiernos estatales y el sector privado, y en coordinación con el CENACE local, los estados podrían desarrollar o encargar una versión regional del estudio de la Zona Competitiva de Energías Renovables de México para determinar las mejores áreas para las subastas regionales y los proyectos renovables con un PPA único. El estudio podría analizar la red de transmisión actual y los refuerzos necesarios. El estudio podría proporcionar una lista de zonas adecuadas que los Estados podrían ayudar a pre-aprobar en términos de requisitos medioambientales y sociales, y con la aportación del operador del sistema se priorizarían determinadas zonas para mejorar la confiabilidad del sistema. 


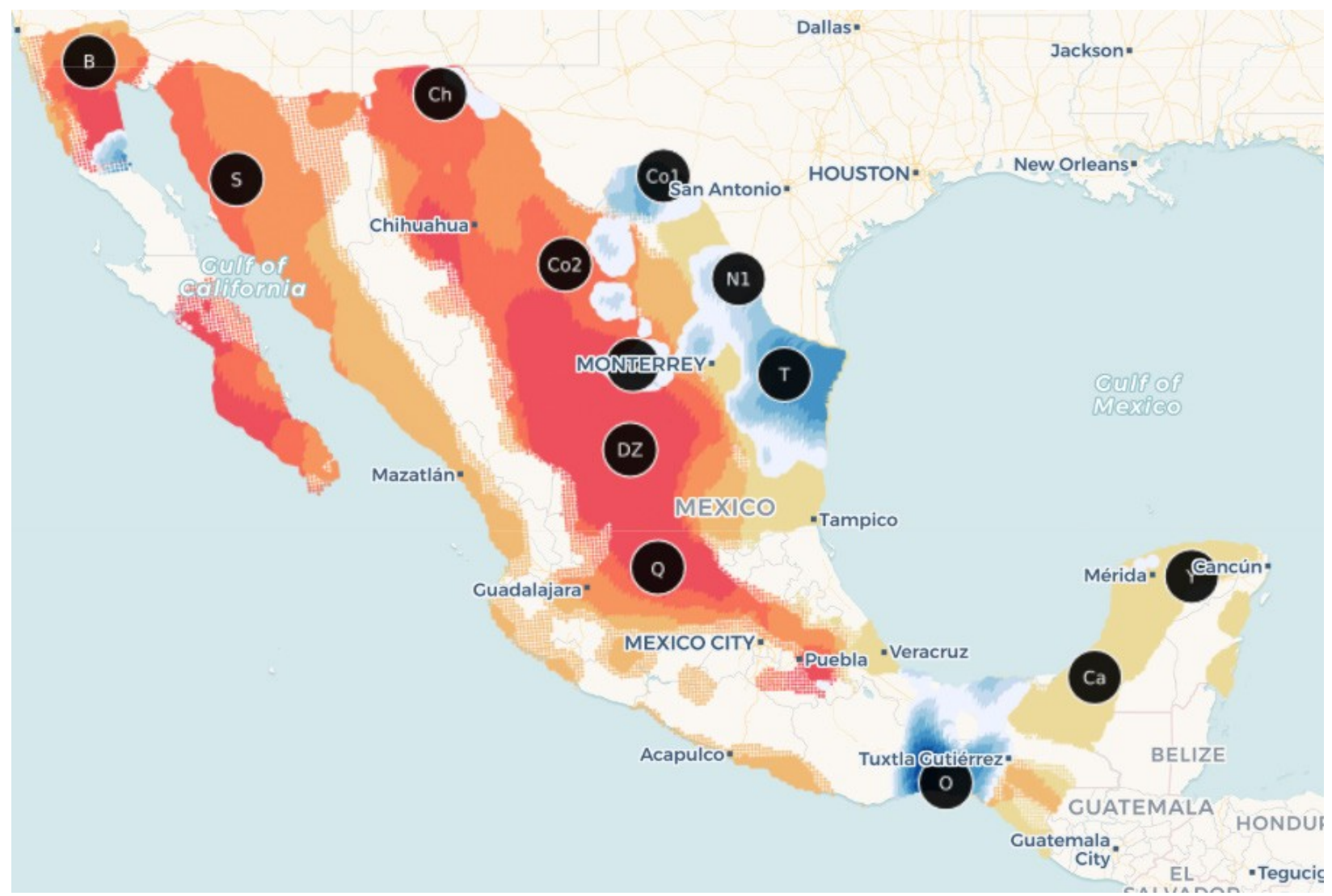

Figura 9. Resultados del análisis de la Zona de Energías Renovables de México

Nota: Los colores amarillo, naranja y rojo muestran el nivel de recurso de irradiación solar, y los tonos de azul representan el nivel de recurso eólico. El color más oscuro representa un mayor recurso. Fuente: NREL

Los Estados pueden utilizar los conocimientos locales y, junto con los datos sobre

recursos, las capacidades técnicas y la experiencia en modelización del NREL, acelerar

la interconexión de las zonas favorables para desarrollar una serie de programas de

energía renovable a gran escala en la región peninsular.

\subsubsection{Subastas regionales de energía limpia}

La creciente popularidad de las subastas de energías renovables (también llamadas a veces «subastas inversas») en todo el mundo se debe a su eficacia como enfoque impulsado por el mercado que puede atraer grandes cantidades de inversión para múltiples proyectos a precios bajos y sin proporcionar costosos subsidios (IDB 2019). El diseño de las subastas tiene muchas características que pueden modificarse para satisfacer las necesidades de un país o región, como pueden ser el tipo de tecnología, la ubicación geográfica y los servicios necesarios con condiciones específicas. La estrategia de subasta basada en la cantidad de energía es quizás la más popular. El volumen subastado puede determinarse en función de la capacidad máxima que puede albergar el sistema existente. En muchas subastas, como en Alemania, México y Perú, se han aplicado límites de capacidad específicos para cada zona, basados en las limitaciones de la red de transmisión. Incluso pueden establecerse límites de capacidad específicos por zona para cada tecnología, como en Kazajistán, donde la solar y la eólica se distribuyen entre las regiones (IRENA 2019). En México, las subastas a largo plazo se crearon como mecanismo impulsor de la Ley de la Industria Eléctrica para permitir al proveedor del servicio básico (servicio básico de la CFE) celebrar contratos a largo plazo, utilizando un mecanismo competitivo para satisfacer sus necesidades futuras de 
capacidad, energía eléctrica y certificados de energía limpia. Las subastas en México se crearon también para permitir que las entidades del sector privado responsables de la carga participaran en este proceso, una vez que se estableciera una cámara de compensación. La cámara de compensación sería la entidad independiente que puede actuar como contraparte entre vendedores y compradores en las subastas a largo plazo, evaluando la credibilidad financiera de los participantes en el mercado y distribuyendo el riesgo. Para los compradores del sector privado, la cámara de compensación podría garantizar una fuente estable de pagos importante para apoyar el financiamiento necesaria para desarrollar las nuevas centrales eléctricas. El periodo de validez de los contratos derivados de las subastas a largo plazo era de 15 años para la energía eléctrica y la capacidad y de 20 años para los certificados de energía limpia (CENACE).

Un mecanismo para dirigir los proyectos a las zonas de necesidad, principalmente con congestión de transporte, fue la introducción de ajustes de precios nodales. Un mecanismo de ajuste de precios nodales ayuda a incentivar el desarrollo de proyectos allí donde la generación es más necesaria (por ejemplo, los estados peninsulares). Según BloombergNEF, «las diferencias nodales regionales jugaron un papel importante en la decisión de las ofertas ganadoras» en la primera subasta que condujo a casi $1 \mathrm{GW}$ de proyectos en el estado de Yucatán (Alves 2016a). Las diferencias nodales regionales jugaron un papel menos importante en la tercera subasta porque las dos primeras subastas ayudaron a corregir los desequilibrios regionales entre la oferta y la demanda (Demoro 2017; del Río 2019). La primera y la segunda subasta de energía limpia de México estaban restringidas al servicio básico de la CFE como adjudicatario exclusivo, mientras que la tercera estaba abierta también a los compradores privados.

Históricamente, los usuarios calificados se han enfrentado a un proceso de negociación y contrato bilateral largo, costoso y no estandarizado con los generadores si querían obtener energía limpia, un fenómeno que la subasta de energía limpia dirigida por el sector privado fue diseñada para solucionar. Según Bravos Energy, el interés de los generadores y de los tomadores fue alto para una primera subasta privada nacional, que entró en su fase final en marzo de 2020 cuando COVID-19 llegó a México.

La riqueza de los recursos de energía renovable en los estados peninsulares y el interés demostrado por el sector privado en el desarrollo de esos recursos tras la primera subasta de energía indican que las futuras subastas de energía dirigidas por el sector privado o por el público pueden aportar más energía limpia de bajo costo a la región. Los gobiernos estatales pueden desempeñar un papel importante en el despliegue de las subastas estatales y/o regionales, registrándose primero como usuario calificado y, junto con el sector privado, convirtiéndose en compradores en la subasta. En segundo lugar, los Estados pueden ayudar asegurando el terreno y ayudando a pre-aprobar las zonas en función de los requisitos medioambientales y sociales. Los Estados también pueden colaborar con expertos técnicos, organizaciones no gubernamentales y financieros para ayudar a desarrollar los mecanismos de mercado y financiamiento necesarios. No obstante, siguen existiendo retos para un enfoque regional de subastas dirigido por el sector privado, entre ellos (Villarreal y Pavlovic 2020):

1. En las regiones con limitaciones de transmisión, como los estados peninsulares, la gran generación renovable adicional desarrollada a través de subastas probablemente también requerirá inversiones en transmisión. La CFE y el CENACE participan en la toma de decisiones del sistema de transmisión; sin su cooperación, incluso la inversión en transmisión del sector privado se enfrenta a obstáculos. Una alternativa sería diseñar una subasta limitada para las regiones que no requieren inversiones en transmisión, lo que podría excluir por completo a la región peninsular. Además, los estados pueden facilitar el uso de terrenos estatales que estén en buenas zonas de interconexión para facilitar el proceso y reducir sus contratos de energía.

2. Mientras que los gobiernos estatales podrían ser potenciales facilitadores de las subastas de energía limpia, los propios gobiernos son vistos como riesgosos dada su histórica y fluctuante solvencia. 
3. Las recientes políticas del CENACE y la SENER (señaladas anteriormente) añaden una importante incertidumbre al sector de las energías renovables en México, que los potenciales participantes tendrán que considerar en sus contratos. Es posible que muchos no participen debido a esta barrera.

4. La supresión de la demanda de electricidad a causa de la COVID-19 ha provocado un descenso de los precios de la energía, lo que dificulta la competencia de las energías renovables, al menos a corto plazo. En la región peninsular, donde el suministro de gas natural es escaso y el crecimiento económico continúa, puede ser un factor menos importante.

5. Las subastas de energía renovable son más valiosas para todas las partes cuando el volumen de generadores y compradores es grande debido a la complejidad y el costo inherentes de la transacción. Las subastas regionales más pequeñas pueden no tener un volumen suficiente para justificar estos costos.

6. En el caso de los múltiples generadores y compradores en una subasta de energía limpia, es necesario contar con un mecanismo de compensación que reduzca los riesgos y ofrezca las garantías requeridas por todas las partes en el contrato.

La reforma energética mexicana a través de la Ley de Electricidad permite la realización de subastas energéticas estatales y/o regionales. Aunque todavía no se ha creado este tipo de subastas, existe un gran interés por parte de los agentes públicos y privados. Para tener éxito hay que tener un diseño y una aplicación cuidadosos con las aportaciones de los gobiernos locales, el sector privado, las comunidades indígenas, las agencias federales y los expertos financieros y energéticos.

\subsubsection{PPA único para usuarios calificados}

Mientras que los tribunales se han puesto del lado de los generadores privados y han frenado los decretos del CENACE y la SENER, ${ }^{6}$ los generadores del sector privado y los compradores industriales están volviendo al modelo de un simple PPA entre un generador y un comprador. Para que estas opciones funcionen, los usuarios deben ser en general grandes consumidores de energía. Esta solución también podría ser utilizada por los estados que se registren como usuarios calificados. ${ }^{7}$ Uno de los problemas de esta solución es la necesidad de tiempo, conocimientos y recursos para comprender y asegurar la elección óptima al mejor precio, lo que puede disuadir a los posibles consumidores interesados. Los consumidores de menor tamaño que no pueden registrarse como usuarios calificados deben buscar otras alternativas. Como se menciona en la sección de subastas, los Estados podrían impulsar el despliegue de las energías renovables ayudando a localizar las zonas óptimas para el desarrollo, trabajando en la aprobación previa de estas zonas y, en última instancia, como adjudicatario de proyectos específicos.

\subsubsection{Contratos para demanda agregada}

Los clientes más pequeños que no pueden optar a los PPA simples podrían recurrir a la contratación agregada. En un modelo de contratación agregada, los consumidores pueden combinar sus necesidades individuales de energía para optar a opciones y precios que de otro modo no estarían a su alcance. Normalmente, las empresas se plantean la agregación para asegurarse precios de electricidad

\footnotetext{
${ }^{6}$ El 3 de febrero de 2021, la Suprema Corte de Justicia de la Nación falló en contra de la Política de Confiabilidad, Seguridad, Continuidad y Calidad del Sistema Eléctrico Nacional de la SENER. La decisión a favor de la Comisión Federal de Competencia alegó que la SENER se extralimitó en sus funciones y socavó la competencia al fortalecer indebidamente a la empresa nacional de servicios públicos (CFE), propiedad del gobierno (Berrera 2021).

${ }^{7}$ Los usuarios caalificados son usuarios finales de electricidad que demandan al menos $1 \mathrm{MW}$.
} 
competitivos, acceder a opciones de energía renovable y recibir orientación sobre las opciones de compra disponibles. Los Estados de México pueden ayudar a coordinarse con la comunidad empresarial para desarrollar y ofrecer opciones de adquisición agregada. Dependiendo de la capacidad instalada de los sistemas renovables, éstos se calificarían como energía a gran escala o DG.

Un tipo de contratación agregada que se ha desarrollado en México es el Acelerador de Inversiones en Energía Limpia (CEIA). ${ }^{8}$ Este programa ha colaborado estrechamente con la Asociación Mexicana de Parques Industriales en el desarrollo de un proceso para lanzar una solicitud de propuestas para la instalación de DG FV que suministre energía a múltiples empresas arrendatarias. De este modo, se aprovechan las economías de escala para permitir un precio de oferta mucho más bajo que el que se presentaría de otro modo. Esto, a su vez, facilita el financiamiento del proyecto. Además, el CEIA actúa como agente de confianza tanto del cliente como de los promotores, de manera que los clientes, que probablemente saben muy poco sobre el sector eléctrico solar, pueden sentirse seguros de que no serán presa de actores sin escrúpulos y de que están recibiendo una propuesta justa y servicios cualificados.

El modelo CEIA podría servir de base para crear modelos de contratación agregados con el tipo de características encontradas de los sectores comercial e industrial en los estados de la península de Yucatán. Campeche, Yucatán y Quintana Roo pueden desempeñar muchas funciones para fomentar el desarrollo acelerado de las energías renovables a gran escala. Los gobiernos estatales y algunos municipios podrían registrarse como usuarios calificados. Los Estados podrían educar al público, crear incentivos fiscales y de otro tipo, y trabajar con la asociación industrial y comercial y la empresa nacional de servicios públicos para encontrar soluciones óptimas.

\subsubsection{Ejidos solares}

Un ejido o «propiedad comunal» es una zona de tierra comunal utilizada principalmente para la agricultura, en la que los miembros de la comunidad cultivan parcelas designadas y mantienen colectivamente las explotaciones comunales. Aunque esta era la intención original y en su día fue una descripción precisa de la actividad ejidal, hoy en día muchas propiedades ejidales en México están abandonadas, sin que se realicen actividades agrícolas ni otras actividades económicas. Los ejidos podrían beneficiarse al permitir desarrollar proyectos de energía renovable in situ.

En todo México hay ejidos que podrían beneficiar a sus comunidades permitiendo el uso de algunas de sus tierras para proyectos de energía renovable, en particular proyectos solares. Los ejidos solares podrían proporcionar a los propietarios de los ejidos (ejidatarios) opciones de ingresos nuevos o adicionales donde sus tierras ya no son utilizables (es decir, la minería de piedra y grava abandonada, las áreas sin acceso al agua y otros sitios agrivoltaicos potenciales) o proporcionar ingresos adicionales diversificados y estables a los ejidatarios agrícolas y ganaderos sin perturbar sus operaciones normales. Estos proyectos se diseñarían de forma similar a un proyecto PPA único. Los gobiernos estatales pueden volver a desempeñar muchos papeles en la promoción de esta solución. Por ejemplo, los estados o municipios podrían convertirse en compradores de la electricidad generada por el proyecto ejidal. Los Estados también podrían ayudar con la educación de los ejidatarios y como promotores con las instituciones financieras y ayudando a diseñar programas y procesos para facilitar la inversión. Dependiendo del tamaño de los sistemas instalados en los ejidos, éstos se calificarían como sistemas de DG o de energía a gran escala.

\footnotetext{
${ }^{8}$ El CEIA es un consorcio tripartito sin ánimo de lucro formado por el NREL, el Instituto de Recursos Mundiales y Allotrope Partners para catalizar la adquisición de energía renovable por parte del sector privado (tanto de GD como de energía renovable a gran escala) en varios países, incluido México.
} 


\subsection{DG}

La DG puede proporcionar beneficios económicos a muchos consumidores residenciales y no residenciales de la Península al reducir sus costos energéticos. La ley mexicana define la DG como los generadores de menos de $500 \mathrm{~kW}$ conectados a la red de distribución. En junio de 2020, la energía fotovoltaica representaba el 99.28\% de todos los contratos de DG en México (RIC Energy 2021).

Debido a los elevados precios de la electricidad, en la Península se ha instalado un importante número de sistemas fotovoltaicos en los últimos años, con más de 10.600 (Tabla 2) que estaban en funcionamiento en junio de 2020. Mérida, la capital del estado de Yucatán, representa más del 50\% de todos los sistemas fotovoltaicos de DG en la Península (CFE). Yucatán tiene una población mayor que los otros dos estados de la Península, así como un mayor número de sistemas fotovoltaicos de DG per cápita. Yucatán tiene 3.8 veces más sistemas fotovoltaicos per cápita que Campeche y 2.6 veces más que Quintana Roo.

Tabla 2. Generación solar distribuida instalada (2017-junio 2020)

\begin{tabular}{|c|c|c|c|}
\hline Estado & $\begin{array}{c}\text { Total de sistemas } \\
\text { fotovoltaicos }\end{array}$ & $\begin{array}{c}\text { Capacidad total } \\
\text { instalada (MW) }\end{array}$ & $\begin{array}{c}\text { Tamaño medio del } \\
\text { sistema fotovoltaico (kW) }\end{array}$ \\
\hline Campeche & 871 & 6.28 & 7.2 \\
\hline Quintana Roo & 2220 & 11.82 & 5.3 \\
\hline Yucatán & 7513 & 50.54 & 6.7 \\
\hline Total & 10604 & 68.64 & 6.5 \\
\hline
\end{tabular}

Fuente: CRE

Mérida, Yucatán, es la única jurisdicción de la Península que ofrece incentivos para los sistemas fotovoltaicos de DG. Las empresas que instalen un sistema fotovoltaico que cumpla los requisitos pueden obtener un descuento de entre el 5\% y el $15 \%$ en sus impuestos sobre la propiedad. El gobierno de Mérida estima que las instalaciones anuales han aumentado 20\% desde la institución del incentivo (Diario de Yucatán 2019).

Como ejemplo de las oportunidades de negocio de la DG que surgen en la Península para aprovechar los altos precios de la energía y los buenos recursos solares, en 2020 se puso en marcha un nuevo programa llamado BANVERDE en el estado de Quintana Roo. Este programa ofrece un financiamiento de hasta el $100 \%$ de los sistemas fotovoltaicos de DG para consumidores no residenciales, ya que sus tarifas eléctricas no están subvencionadas. El programa está financiado por un grupo de inversión privado con sede en Estados Unidos (WRB Enterprises), que ha puesto en marcha programas similares en varios otros estados mexicanos. En Quintana Roo, el programa incluye un capital de \$15 millones para el financiamiento parcial o total de los sistemas fotovoltaicos de DG. El consumidor no residencial firma un PPA con BANVERDE que le proporciona una tarifa eléctrica con descuento sobre la tarifa de la CFE. El cliente se convierte en el propietario total del sistema al final del contrato, y en el caso de Quintana Roo, BANVERDE ofrece como incentivo adicional la exención del pago total del consumo eléctrico durante los primeros 6 meses (Estado de Yucatán 2021).

Esta sección destaca los programas y políticas de DG existentes y potenciales para los clientes residenciales, comerciales e industriales de la Península.

\subsubsection{Energía solar residencial distribuida}

Según Iniciativa Climática de México, el 98.75\% de las tarifas eléctricas residenciales en México están subsidiadas, mientras que los consumidores conocidos como "de alto consumo" (también conocidos como clientes DAC), constituyen el $1.25 \%$ de los clientes residenciales restantes y no reciben ningún subsidio. 
Los clientes de alto consumo, junto con los clientes comerciales e industriales, aportan el $18 \%$ del subsidio a los consumidores residenciales; el resto lo paga el gobierno federal. El subsidio eléctrico de México en 2019 fue de 52000 millones de pesos, y el gobierno federal presupuestó 70,000 millones de pesos, es decir, un aumento de $31 \%$, para 2020 (Baz et al. 2015). ${ }^{9}$ El costo nivelado de la electricidad (LCOE) para un sistema de $10 \mathrm{~kW}$ en cualquier lugar de la Península es al menos un 34\% más bajo que la tarifa de alto consumo (dependiendo de la ubicación, el porcentaje puede ser mayor) (CFE). Los datos también muestran que el LCOE en los tres estados, es aproximadamente igual a las tarifas residenciales subsidiadas de la CFE.

Los clientes de la tarifa de alto consumo tienen la mayor tasa de adopción de energía fotovoltaica de todos los clientes residenciales, pero son solo un pequeño porcentaje del total de clientes. Una combinación de precios más bajos de la energía fotovoltaica, programas específicos del gobierno e incentivos podría acelerar significativamente la adopción de la energía fotovoltaica de DG para los consumidores residenciales en México.

\subsubsection{Hogares solares}

Hogares Solares es un modelo de negocio y un mecanismo de financiamiento propuestos por la organización medioambiental local sin ánimo de lucro Iniciativa Climática de México, para transformar los subsidios gubernamentales a la electricidad en incentivos para que los clientes residenciales adopten sistemas fotovoltaicos. El objetivo a largo plazo es reducir los subsidios actuales que paga el gobierno federal sin aumentar las tarifas de los clientes. Según el programa, un porcentaje de los propios subsidios actuales se desviaría para reducir el costo de los sistemas fotovoltaicos en los tejados de los clientes que optaran por el programa. El subsidio para los clientes que adopten la energía fotovoltaica se reduciría, pero sus facturas de electricidad no aumentarían significativamente debido a la reducción del consumo de energía proveniente de la red que proporcionaría la energía solar.

Actualmente, el programa del Fondo para la Eficiencia Energética (FIPATERM) de la CFE está analizando la posibilidad de financiar proyectos piloto en algunas ciudades del norte de México. Los proyectos piloto servirían para ayudar a los consumidores a comprender mejor los beneficios económicos, incluida la reducción del subsidio, y los posibles retos técnicos de un despliegue mayor, incluida la integración de la GD en el sistema distribuido de la CFE. Los estados de la península de Yucatán que estén interesados en analizar el programa de Hogares Solares pueden solicitar la asistencia técnica de Iniciativa Climática de México y sus socios para comprometerse con el FIPATERM y otras fuentes de financiamiento.

\subsubsection{DG para MiPyMEs}

En contraste con el pequeño porcentaje de clientes residenciales que pagan las tarifas eléctricas más altas para su clase de cliente, más del 87\% de las micro, pequeñas y medianas empresas (MiPyMEs) (INEEL e ICM 2019) (173 341 clientes comerciales en los tres estados) pagaron la tarifa comercial más alta en 2018 para su clase de cliente (CFE). Además, las tarifas para clientes comerciales no reciben ningún subsidio. La tarifa que pagan las MiPyMEs es de USD \$0.16 por kWh y es al menos un 22\% superior al LCOE de un sistema fotovoltaico a pequeña escala. ${ }^{10} \mathrm{Si}$ todas las MiPyMEs se convirtieran a DG FV, colectivamente podrían ahorrar entre USD \$27 y \$43 millones cada año (cálculo del NREL).

Para las empresas que instalan sistemas más grandes, la diferencia entre el LCOE y sus tarifas actuales es aún mayor debido a las economías de escala. Según las autoridades estatales, los promotores fotovoltaicos

\footnotetext{
${ }^{9}$ El gobierno federal presupuesta 70000 millones de pesos para subsidio eléctrico en 2020 (Solís 2019).

${ }^{10}$ Las microempresas emplean a 10 o menos personas y obtienen menos de 4 millones de pesos mexicanos de ingresos anuales. «Las pequeñas» empresas emplean de 11 a 50 personas y tienen un ingreso anual de 4.01 a 100 millones de pesos mexicanos (Banco de México 2017).
} 
de la Península han construido sistemas fotovoltaicos de GD de este tamaño y mayores por tan sólo USD $\$ 1.10 / \mathrm{w}$. Suponiendo un precio conservador de USD $\$ 1.25 / \mathrm{w}$, el LCOE de un sistema de $50 \mathrm{~kW}$ es al menos un 35\% inferior a la tarifa eléctrica de un MiPyME.

Los estados de la península pueden trabajar con los promotores solares, los consumidores y las empresas financieras para desarrollar políticas y programas que promuevan estas instalaciones fotovoltaicas de DG y ayuden a reducir la carga energética de un sector crítico de las economías locales.

\subsubsection{Energía solar comunitaria}

La energía solar comunitaria, también conocida como energía solar compartida o huertos solares, es un modelo de despliegue de energía solar distribuida que permite a los clientes -incluidos los clientes domésticos individuales, las empresas y las organizaciones sin ánimo de lucro- comprar o alquilar parte de un sistema solar fotovoltaico compartido más grande fuera de sus instalaciones y compensar su consumo de energía (de forma virtual) con la energía producida por su parte del sistema solar comunitario. Los programas solares comunitarios permiten que varios clientes o «abonados» compren la producción de un solo panel solar fotovoltaico. La energía solar comunitaria sirve a los consumidores residenciales y comerciales que no tendrían el espacio y las condiciones necesarias o los recursos financieros para instalar su propio sistema PV.

Con sus elevados recursos solares, México podría utilizar potencialmente el modelo solar comunitario para aumentar el despliegue de la DG y, en particular, ayudar a alcanzar el objetivo de democratización de la reforma energética, llevando la energía limpia a segmentos de la población distintos de los clientes de alto consumo (que suelen ser hogares de altos ingresos), y potencialmente como mecanismo de reducción de los elevados subsidios a la electricidad, al reducir el número de kWh que recibirían subsidios federales. Los proyectos solares comunitarios también se benefician de las economías de escala y podrían aportar ventajas al operador del sistema (CENACE) para entender, gestionar e integrar mejor la DG en el sistema eléctrico. Si bien la reforma energética permitió la creación de sistemas solares comunitarios, la CRE aún no ha promulgado la regulación necesaria para permitir la medición neta virtual, que es esencial para los programas comunitarios. Los estados de la península podrían plantear colectivamente esta cuestión a la CRE y estudiar la posibilidad de formar asociaciones con la empresa de servicio básico (CFE), el sector privado y las organizaciones sin ánimo de lucro para poner en marcha una serie de proyectos piloto de energía solar comunitaria de $500 \mathrm{~kW}$ en terrenos propiedad del estado o del municipio para comprender los beneficios y sentar las bases para un despliegue mayor.

\subsubsection{DG Opciones de política pública para los Estados de la Península}

La política pública es un mecanismo que las oficinas estatales de energía pueden utilizar para reducir las barreras y promover la inversión para aumentar el despliegue de las tecnologías de DG. El NREL ha examinado previamente el panorama de la política de DG en México y ha publicado un documento que describe las opciones de política basadas en las lecciones aprendidas y las mejores prácticas internacionales.10 Aunque este documento fué escrito con el gobierno federal en mente, algunas de las opciones discutidas podrían adaptarse como base para la legislación patrocinada por el estado para promover y ampliar el mercado de la DG en la región.

1. Reducir las barreras financieras a la adopción de DG mediante incentivos financieros directos y ampliando el acceso a un financiamiento asequible: Las barreras financieras son uno de los mayores obstáculos para la adopción. Los estados de la Península podrían establecer potencialmente incentivos financieros directos en forma de créditos o exenciones fiscales, de forma similar a lo que hace la ciudad de Mérida con el descuento en los impuestos sobre la propiedad para las empresas que instalen tecnologías que cumplan los requisitos. Estos incentivos ayudan a reducir el costo de los sistemas de DG, haciéndolos asequibles para un mayor segmento 
de la población. También se pueden ofrecer incentivos financieros a segmentos específicos, como las poblaciones de bajos ingresos y las microempresas. Este tipo de apoyo ha demostrado ser un mecanismo eficaz para reducir la desigualdad en la adopción de la tecnología fotovoltaica de GD.11 Otra opción es ayudar a ampliar el acceso al financiamiento de las tecnologías de DG. Los costos iniciales de los sistemas fotovoltaicos, aunque en una trayectoria descendente, pueden seguir siendo una barrera para la adopción por parte de algunos clientes. Los préstamos a mediano plazo son eficaces para ayudar a los potenciales adoptantes de la DG a distribuir los costos iniciales a lo largo del plazo del préstamo, pero el financiamiento asequible en los países en desarrollo puede ser difícil de conseguir debido a los altos tipos de interés o a la falta de interés de los bancos comerciales. Aunque al menos un banco de la Península ya ofrece préstamos para sistemas fotovoltaicos de DG, los estados de la Península podrían intervenir y trabajar con los bancos regionales para reducir el riesgo de la inversión y ayudar a los clientes que, de otro modo, no podrían optar a un préstamo comercial. Los estados de la península podrían estudiar la posibilidad de reservar y utilizar recursos estatales y/o asociarse con promotores privados interesados en hacer crecer el mercado de GD PV y crear un fondo rotatorio con el fin de proporcionar financiamiento a algunos sectores de la población.

2. Apoyar el crecimiento de la industria y la calidad de las instalaciones de DG mediante programas de formación de la mano de obra: Un obstáculo que también se encuentra en el incipiente mercado de DG PV es la calidad del producto instalado debido a la escasez de profesionales formados con experiencia en instalaciones PV. Los estados podrían aumentar la calidad de las instalaciones fotovoltaicas de DG y la confianza de los potenciales clientes y financiadores introduciendo programas de formación y certificación con la ayuda de instituciones técnicas y universidades.

3. Promover el conocimiento público de las tecnologías de DG: Otro papel que podrían desempeñar los Estados es el de aumentar la concienciación y la educación del público sobre la DG solar, incluyendo: conceptos básicos de irradiación y generación de electricidad, seguridad e instalación adecuada, beneficios económicos y medioambientales, y oportunidades de creación de empleo. La promoción podría realizarse mediante la creación de un sitio web y el uso de campañas públicas que podrían incluir la promoción de los incentivos y programas estatales que los estados puedan adoptar.

4. Defender la agilización de los procesos de interconexión y tarifas de compensación atractivas para la DG: Los tres estados también podrían unirse para trabajar con la CFE y el gobierno federal para adoptar prácticas de interconexión y tarifas de compensación que ayuden a promover la adopción y expansión del mercado en la Península.

\subsubsection{Eficiencia energética}

La implementación de programas y medidas de eficiencia energética en la Península de Yucatán puede reducir el consumo de electricidad en edificaciones e instalaciones residenciales, comerciales e industriales, a la vez que crea nuevas oportunidades de negocio y empleos bien remunerados. La eficiencia energética, junto con el despliegue de generación limpia, se considera un componente clave de los programas de desarrollo sustentable de a largo plazo para los tres estados de la Península. La inclusión de políticas de eficiencia energética en sus planes energéticos y la adopción y aplicación de medidas de eficiencia energética complementan otras políticas relacionadas con la energía, como el aumento de la generación limpia, la reducción de los precios de la energía y el aumento de la seguridad, la confiabilidad y la resiliencia energética en la región. No obstante, existen algunas barreras clave para la aplicación de la eficiencia energética que deben ser comprendidas y reducidas. Estas barreras no son exclusivas de la 
península o de México e incluyen: el acceso a un financiamiento asequible, ${ }^{11}$ la elevada inversión inicial, los costos de operación y mantenimiento, la escasez de incentivos fiscales disponibles y la falta de conocimientos técnicos de las instituciones financieras y de los consumidores de energía.

En México, la Comisión Nacional para el Uso Eficiente de la Energía (CONUEE) es un órgano administrativo descentralizado de la SENER, cuyo principal objetivo es promover la eficiencia energética y actuar como órgano técnico para el uso sustentable de la energía. Entre sus competencias, cabe destacar las siguientes:

- Emisión y verificación de las disposiciones administrativas generales relativas a la eficiencia energética y a las actividades que incluyen el uso sustentable de la energía.

- Emisión y revisión de Normas Oficiales Mexicanas en materia de eficiencia energética.

- Asesoría técnica en materia de aprovechamiento sustentable de la energía a las dependencias y entidades de la Administración Pública Federal, así como a los gobiernos de las entidades federativas y municipios que lo soliciten.

- Elaboración y publicación de libros, catálogos, manuales, artículos e informes técnicos sobre los trabajos realizados en el ámbito de la eficiencia energética.

- Realizar los estudios técnicos necesarios para determinar los patrones y la intensidad del consumo de energía por uso final, tipo de usuario, actividad económica y región del país.

- Promoción y disposición de la instrumentación voluntaria de los sistemas de gestión de la energía según procedimientos, protocolos o normas reconocidos internacionalmente.

- Creación y fortalecimiento de las capacidades de las instituciones públicas y privadas de carácter local, estatal y regional para que apoyen los programas y proyectos de eficiencia energética en los servicios municipales y en las pequeñas y medianas empresas.

- Identificación de las mejores prácticas internacionales en materia de programas y proyectos de eficiencia energética y promoción de las prácticas aplicables en el territorio nacional.

En el marco del Programa de Eficiencia Energética para la Administración Pública Federal, la CONUEE emite y publica en el Diario Oficial de la Federación, los documentos que establecen y regulan las diversas acciones de ahorro de energía que deben realizar las instituciones federales.

A nivel subnacional, las normas oficiales mexicanas (NOM) y las normas de aplicación voluntarias emitidas por la CONUEE sólo son obligatorias si los estados deciden adoptarlas. Con respecto a las normas de eficiencia energética en las edificaciones estatales, varios estados mexicanos han redactado sus normas estatales con la adopción de las normas realizadas por la CONUEE y presentan la NOM contenida en ellas como obligatoria. La autonomía estatal permite que cada estado y municipio decida dentro de su propio marco legal si requiere o no la NOM.

En esta sección, analizamos algunos enfoques útiles para ayudar a los estados peninsulares en el proceso de elaboración de políticas públicas. Seguimos con discusiones más detalladas sobre la política de eficiencia energética y la información sobre la elaboración de programas en los sectores prioritarios de las viviendas de bajos ingresos, las edificaciones gubernamentales, las pequeñas empresas y los sistemas de bombeo de agua. Al final del informe, incluimos el Anexo A con información técnica más detallada que

\footnotetext{
${ }^{11}$ En el sector financiero comercial, muchas instituciones desconocen los beneficios y la posibilidad de financiar proyectos de eficiencia energética. En muchos países, estas barreras se han reducido con formación y seminarios para los bancos comerciales sobre tecnologías de eficiencia energética que abren la puerta a los fondos para estos proyectos.
} 
complementa el debate. Los trabajos futuros de eficiencia energética en la península podrían incluir la revisión y adopción de las NOM de la CONUEE y otras mejores prácticas internacionales, el diseño de programas de promoción de la eficiencia energética en diversos sectores de la economía, la educación de los consumidores y de las instituciones financieras, y las auditorías energéticas.

\subsubsection{Enfoques políticos de la eficiencia energética}

Decidir cómo y dónde empezar a aplicar los programas requiere una cuidadosa planificación y priorización. Los métodos de divulgación y evaluación, por ejemplo, desempeñan un papel importante y deben analizarse cuando se plantean nuevas políticas. (Aznar, Logan, Gagne, Chen - 2019 Promover la eficiencia energética en los países en desarrollo). Las inversiones en eficiencia energética pueden aportar beneficios concretos en cuanto a la reducción de la demanda global de energía y el cumplimiento de los objetivos nacionales de seguridad energética y protección del medio ambiente (USAID 2020). Además, los programas e inversiones en eficiencia energética pueden explorarse junto con los incentivos y programas existentes para el despliegue de la DG como soluciones sistemáticas a largo plazo para reducir los subsidios federales a la electricidad de forma económica y eficiente.

El Consejo Estadounidense para una Economía Energéticamente Eficiente ha creado una serie de documentos que facilitan el análisis y la toma de decisiones para diseñar políticas de eficiencia energética (ACEEE). En concreto, han diseñado una herramienta que menciona los siguientes pasos para desarrollar el tema de la eficiencia energética en las ciudades, que aporta importantes lecciones a los estados de la península:

- Desarrollar, aplicar y comunicar una visión de eficiencia energética para el Estado.

- Aumentar la eficiencia energética en las operaciones del gobierno local.

- Aumentar la eficiencia energética de las edificaciones existentes.

- Trabajar en la implementación de prácticas, equipos y materiales energéticamente eficientes en las nuevas construcciones.

- Promover el transporte con eficiencia energética.

- Aprovechar y maximizar los programas federales.

A la hora de desarrollar programas de eficiencia energética, es importante abordar las barreras que podrían hacer descarrilar la adopción. La siguiente es una lista útil a tener en consideración (Cooperación Alemana y GIZ 2018):

1. Desarrollar un portal con información sobre modelos empresariales de éxito que promuevan la adopción de la eficiencia energética:

A. Difundir las experiencias de otros países en la implantación y desarrollo de mercados e industrias específicas.

B. Identificar las necesidades de desarrollo de capacidades de cada sector y definir un programa conjunto.

C. Llevar a cabo reuniones de grupos de trabajo con los principales líderes del sector para identificar si existen barreras específicas que no se hayan detectado en este estudio.

2. Desarrollar talleres de divulgación sobre las tecnologías disponibles para proporcionar formación para la aplicación de las mejores prácticas por el tipo de industrias cubiertas: 
A. Incorporar sistemas de herramientas tecnológicas con la participación de instituciones académicas y de investigación para crear un programa de «preparación de formadores» para ampliar el alcance y la adopción de estas herramientas.

B. Identificar las situaciones de restricción de las infraestructuras energéticas y sus posibles soluciones.

C. Llevar a cabo un análisis de la aplicación de las auditorías financiadas con fondos públicos para identificar oportunidades.

3. Realizar un análisis en profundidad de los problemas de financiamiento:

A. Identificar si el origen es un problema de acceso al financiamiento, la falta de capacidad de la banca comercial o los costos inherentes al financiamiento.

B. Desarrollar líneas de financiamiento mediante el apoyo de bancos de desarrollo nacionales, regionales o internacionales y la formación de bancos comerciales.

C. Analizar las estrategias para facilitar el acceso al crédito a los pequeños industriales para la compra de equipos eficientes.

D. Identificar con los interesados el tipo de financiamiento que facilitaría una decisión favorable.

E. Definir contratos de rendimiento y de garantía sobre los riesgos asociados y líneas de crédito vinculadas a los tipos de interés favorables. Creación de líneas específicas en la banca de primer nivel para que los bancos comerciales dispongan de líneas de crédito vinculadas a la compra de equipos eficientes certificados o líneas de crédito para la implantación de procesos productivos más eficientes.

F. Evaluar el acceso y establecer asociaciones con instituciones bancarias internacionales de desarrollo para crear fondos de garantía que reduzcan el riesgo y su percepción.

G. Evaluar la reducción o eliminación de otras cargas fiscales para crear una vía de incentivos para la adopción de estas tecnologías.

H. Desarrollar regímenes especiales de amortización para los diferentes componentes del capital. Esto atraerá a las principales instituciones bancarias a participar activamente en estos programas.

4. Crear directorios de empresas de servicios energéticos (ESE) y un fondo de garantía para facilitar el financiamiento y el apoyo a las ESE:

A. Identificar las necesidades de desarrollo de capacidades para la existencia de las ESE.

B. Mejorar el alcance y cerrar la brecha haciendo que las ESE y las industrias trabajen juntas de forma cohesiva.

5. Crear bases de datos de equipos y proveedores en el mercado local e internacional. Identificar las tecnologías de vanguardia que mejoran el estado de la técnica.

6. Analizar la viabilidad de que el Estado opere como garante de manera que se reduzca el riesgo de las empresas privadas y que esto les permita acceder a créditos a tasas más convenientes.

\subsubsection{Eficiencia energética en beneficio de los hogares con bajos ingresos}

Los consumidores residenciales de bajos ingresos de los países en desarrollo pueden tener que decidir entre pagar la factura de la luz o renunciar a otros servicios o necesidades básicas como la calefacción, las medicinas, los alimentos o la educación. Los países de la Organización para la Cooperación y el Desarrollo Económico han abordado estas necesidades contrapuestas mediante una serie de enfoques que 
se dividen en dos grandes grupos: (1) subsidios al servicio eléctrico proporcionados como ayuda a través de una reducción en las facturas de electricidad para los consumidores con bajos ingresos, y (2) inversiones en eficiencia energética que proporcionan una reducción a largo plazo de la energía que el cliente paga en su factura. Los subsidios al servicio eléctrico podrían seguir siendo necesarios cuando las políticas y programas de eficiencia energética no llegan a todos los consumidores que los necesitan (Aznar, Logan, Gagne, Chen - 2019 Promover la eficiencia energética en los países en desarrollo).

El subsidio al servicio eléctrico en México reduce también la capacidad del gobierno para invertir en otras necesidades y programas nacionales. Las medidas y los programas de eficiencia energética dirigidos a los clientes con bajos ingresos pueden tener el potencial de reducir el consumo de electricidad y, por lo tanto, el gasto gubernamental continuo necesario para los subsidios eléctricos. Los estados de la península pueden analizar una serie de medidas y programas de eficiencia energética para los ciudadanos de bajos recursos con el fin de comprender cuáles son las más impactantes. Una opción podría incluir mandatos de códigos de construcción de eficiencia energética para las viviendas de bajos ingresos, considerando incluso la instalación de energía fotovoltaica distribuida. El aumento previsto del uso del aire acondicionado en la Península de Yucatán y la consiguiente carga y costo adicionales de electricidad subrayan la importancia de las medidas de eficiencia energética significativas y rentables para los consumidores residenciales; especialmente para los clientes de bajos ingresos.

\subsubsection{Eficiencia energética en edificaciones y servicios públicos}

El uso de la energía es una de las partidas presupuestarias más importantes para los estados y municipios mexicanos. Algunos de los ejemplos más notables son el alumbrado público, los servicios de agua (bombeo, riego, tratamiento de aguas residuales) y el uso de electricidad en oficinas públicas, escuelas y hospitales. Los programas estatales de eficiencia energética para edificaciones e instalaciones públicas son importantes para reducir estos costos. La aplicación efectiva del programa requiere consultas con varios ministerios y la empresa que proporciona el servicio eléctrico. Se puede aprender mucho de los programas federales y estatales de eficiencia energética existentes en México. Por ejemplo, la CONUEE tiene un Programa de Eficiencia Energética en la Administración Pública Federal que promueve actividades de ahorro y uso eficiente de la energía en 1064 edificaciones del gobierno federal. En 2015, Los Gobiernos Locales por la Sustentabilidad, en coordinación con la CONUEE, implementaron en los estados de Jalisco y Tabasco un programa similar al de la Administración Pública Federal para las edificaciones públicas bajo la administración de estas entidades (BID, Hoja de Ruta 2020 para el Programa de Energía del Estado de Quintana Roo).

Actualmente, los estados de Campeche, a través de la Secretaría de Desarrollo Energético Sustentable, y Yucatán, a través de las Secretarías de Desarrollo Sustentable y de Desarrollo Económico y del Trabajo, participan en el Programa de Acción Climática para Ciudades, apoyado por el Acelerador de Eficiencia Energética en Edificaciones (PACC-BEA). El programa es implementado por Sustentabilidad para México AC en alianza con el Instituto de Recursos Mundiales México. El PACC-BEA tiene como objetivo apoyar y asesorar a los gobiernos locales en el diseño y aplicación de políticas de eficiencia energética en el sector de la construcción, así como contribuir al entendimiento entre los gobiernos, el sector privado y el sector social para trabajar juntos en la consecución de edificaciones más eficientes, sustentables y confortables. El programa ha creado hasta ahora alianzas con el sector privado y organizaciones con enfoque de sustentabilidad para generar políticas públicas de eficiencia energética en estos estados de la Península.

El PACC-BEA propuso a Campeche como el primer estado bajo el proyecto «Deep Engagement» para contribuir a los objetivos de eficiencia energética del estado. En marzo de 2021, el gobernador de Campeche firmó los lineamientos generales de eficiencia energética para las edificaciones estatales. Las directrices, que se mencionan a continuación, se aplican a la construcción, el arrendamiento, el mantenimiento de inmuebles, la adquisición de equipos, materiales y otros, y establecen los criterios 
técnicos que permiten mejorar la eficiencia y el consumo energético de las edificaciones públicas. También se traducirán en un mejor rendimiento energético, un mayor confort térmico y un ahorro presupuestario gracias al menor consumo de energía en la construcción y el funcionamiento de las edificaciones públicas estatales.

- Implementar un sistema de gestión de la energía.

- Mejorar el rendimiento energético en la iluminación, el aire acondicionado, la ubicación, el aislamiento térmico, el uso diverso y otros usos.

- Aumento de la conformidad térmica y reducción del consumo de energía.

- Reducir las emisiones de gases de efecto invernadero en la construcción y el funcionamiento de las edificaciones públicas.

- Uso prioritario de las energías renovables.

En Campeche, el PACC-BEA también puso en marcha un proyecto piloto denominado «Sistema de Gestión Energética en el Palacio de Gobierno del Estado de Campeche». En este piloto se ha completado el manual del sistema de gestión de la energía que se implementará y está en revisión por la CONUEE. El proyecto piloto incluye el diseño y la implantación de un sistema de gestión energética en el Palacio de Gobierno, que servirá para articular las directrices de eficiencia energética para todas las edificaciones de la administración pública estatal. El proyecto piloto consiste en evaluar el rendimiento energético; racionalizar y reducir el consumo de energía; aplicar acciones de mejora; desarrollar mecanismos de seguimiento; y sentar las bases para un despliegue en todas las edificaciones públicas de la administración pública estatal.

Además de aprovechar los programas federales CONUEE y estatales PACC-BEA de eficiencia de los edificios, los estados pueden iniciar otras dos prácticas que afectan al uso de la energía en las edificaciones gubernamentales: las auditorías energéticas y los códigos de construcción. Las auditorías energéticas son una herramienta importante para que los Estados conozcan su base de carga energética. Los estados de la península también podrían utilizar herramientas como la del Laboratorio Nacional Lawrence Berkeley (Berkeley Lab) y Johnson Controls, Inc. La herramienta de selección de eficiencia de edificaciones para la reconversión energética, que proporciona a los propietarios y gestores de edificios comerciales, institucionales y gubernamentales una herramienta de código abierto y fácil de usar para analizar las mejoras de eficiencia convirtiendo los datos de consumo energético mensual disponibles en recomendaciones específicas y rentables para mejorar la eficiencia energética. Los códigos de edificación influyen en los métodos de construcción de los edificios, en las tecnologías y los materiales que deben utilizarse, en la seguridad y la durabilidad, y tienen implicaciones en el uso de la energía y el agua.

\subsubsection{Eficiencia energética en las pequeñas y medianas empresas}

Las pequeñas y medianas empresas de México constituyen el $99.8 \%$ del total de empresas, generan el $52 \%$ del producto interior bruto y aportan el $72 \%$ de los empleos formales (Secretaría de Economía). El Balance Nacional de Energía 2009 de la SENER y el Informe Anual 2009 de la CFE muestran que el consumo de energía del sector representa el 17\% del consumo energético del país, que se divide en el $11 \%$ del consumo total de energía térmica nacional y el $47 \%$ del consumo total de electricidad nacional. Una estimación de las medidas de eficiencia energética en este sector estima la viabilidad de conseguir un ahorro de energía eléctrica en las pequeñas y medianas empresas de entre el $10 \%$ y el $20 \%$ (SENER).

Para lograr el mayor ahorro, es necesario coordinarse con la CONUEE en la adopción de normas de eficiencia energética ya establecidas y fomentar el uso de la DG. Los gobiernos estatales pueden ayudar creando programas de eficiencia energética que apliquen las mejores normas y organizando formaciones para proporcionar información a las pequeñas y medianas empresas y a los financieros. 


\subsubsection{Evaluación de la eficiencia energética en los sistemas de bombeo de agua}

El bombeo y el tratamiento del agua es una práctica que consume mucha energía y es un excelente objetivo para las medidas de eficiencia energética. En 2014, la Asociación Nacional de Empresas de Agua y Saneamiento puso en marcha la iniciativa CEEPA y una herramienta ( «Cálculo de la eficiencia energética y el potencial de ahorro de energía en los sistemas de bombeo de agua») que permite a los usuarios identificar las opciones de eficiencia energética más económicas y de mayor impacto y generar informes. Los estados peninsulares pueden utilizar esta herramienta para identificar soluciones energéticas atractivas para el bombeo de agua.

Algunas de las medidas de eficiencia energética y mejores prácticas más importantes para las estaciones de bombeo de agua consisten en la integración de las regulaciones o normas pertinentes, el control y el mantenimiento con la creación de registros en la operación de las estaciones de bombeo de agua, el desarrollo de mejores prácticas y soluciones de inversión para el reemplazo de motores y bombas, la adecuación de las tarifas eléctricas, la adopción de energía distribuida independiente en áreas como los pozos sin acceso al sistema eléctrico, la reducción de pérdidas, el desarrollo y la adopción de planes de mantenimiento integral, entre otros (Cooperación Alemana y GIZ 2017).

\subsubsection{Transporte sustentable}

La electrificación del sector del transporte puede ser un pilar de la descarbonización regional. Los vehículos eléctricos no solo son más eficientes (por unidad "julio" de energía) que los vehículos de gasolina/diesel, sino que no tienen emisiones en el tubo de escape (por ejemplo, NOx, SOx, partículas, etc.) que contribuyen a la mala calidad del aire local y, en general, producen menos emisiones de gases de efecto invernadero que los vehículos convencionales. 12 A pesar de estos beneficios, existen barreras y desafíos para su despliegue, como los costos iniciales más elevados, la posible ansiedad por la autonomía, los inconvenientes de la recarga y el desconocimiento general de los consumidores, que pueden requerir políticas específicas.

En México existen varias políticas federales, estatales y locales que incentivan el despliegue de vehículos de energía avanzada, en concreto vehículos eléctricos, híbridos y de baterías. A nivel federal, la ley federal del impuesto sobre la renta de México exime a los vehículos eléctricos e híbridos de las tasas de venta o importación (Secretaría de Hacienda y Crédito Público 2014). Del mismo modo, una ley federal del impuesto sobre la renta aprobada en 2017 permite mayores deducciones fiscales para los propietarios de vehículos eléctricos e híbridos y ofrece un crédito fiscal del 30\% para la inversión en equipos públicos de suministro de vehículos eléctricos. Más recientemente, el gobierno federal declaró una exención de impuestos de importación a todos los vehículos eléctricos nuevos para el transporte de 10 o más personas y el transporte de mercancías (Secretaría de Gobierno 2020). A nivel estatal, los vehículos eléctricos están exentos de impuestos estatales sobre la propiedad en Yucatán y otros estados. Además, la CFE permite el despliegue de vehículos eléctricos mediante la instalación de un contador especial para los propietarios de vehículos eléctricos que los mantiene en la tarifa doméstica en lugar de la tarifa de alto consumo, de modo que los adoptantes de vehículos eléctricos evitan el aumento del costo de la electricidad.

Por último, la Ciudad de México ha liderado las políticas locales favorables a los vehículos eléctricos: (1) la exclusión de los vehículos eléctricos e híbridos de los procedimientos de verificación vehicular (es decir, estos vehículos pueden circular diariamente); (2) un programa EcoTag que permite a los vehículos eléctricos utilizar las autopistas urbanas a un menor costo; (3) estatus de estacionamiento preferencial; y (4) exenciones para los operadores de transporte público y privado que utilizan vehículos eléctricos de la obligación de renovar su flota cada 10 años (Téllez Martine y Vázquez 2018; Aleatica 2017).

\footnotetext{
${ }^{12}$ Cuanto más limpia sea la combinación de redes, mayor será la reducción de emisiones de los vehículos eléctricos.
} 
En su informe de 2012 para el Instituto de las Américas, Shapiro y Campero identifican cuatro enfoques que los gobiernos municipales pueden adoptar para fomentar la adopción de vehículos eléctricos por parte de flotas privadas y públicas en México (además de las acciones federales y lideradas por la industria) (Shapiro y Campero 2012):

- Establecer normas, códigos y procedimientos que agilicen la instalación y el mantenimiento de las estaciones de recarga junto con la CFE.

- Permitir los vehículos eléctricos en los carriles para vehículos de alta ocupación.

- Establecer un estacionamiento exclusivo para vehículos eléctricos.

- Emular el programa de Ciudad de México que ofrece un incentivo económico y un programa de préstamos garantizados a los taxistas dispuestos a adoptar vehículos eléctricos; y/o ampliar este tipo de programa a otras flotas.

En los estados y ciudades de la península de Yucatán se ha puesto poco énfasis formal en la electrificación del transporte.

La ciudad de Mérida cuenta con el Plan Integral de Movilidad Urbana Sustentable Mérida 2040 en el que se establecen objetivos, estrategias y acciones de movilidad urbana. Ninguno aborda explícitamente la electrificación del transporte, pero la electrificación de los vehículos podría contribuir a varias estrategias, en particular (Ayuntamiento de Mérida 2019):

- Optimización e innovación de tecnologías en el sistema de transporte público, con énfasis en la renovación de las flotas para cumplir los objetivos de eficiencia energética y reducción de emisiones.

- Se hace hincapié en el control y la reducción del impacto medioambiental (por ejemplo, las emisiones) de los vehículos privados.

El Plan Integral de Movilidad Urbana Sustentable señala que el 47\% del reparto modal en Mérida es el transporte público y el $31 \%$ los vehículos privados (con un notable incremento de las motocicletas), lo que sugiere que estos modos de transporte podrían ser un objetivo para los pilotos o programas de electrificación de vehículos en caso de que la ciudad esté interesada en esta acción.

En Quintana Roo, no hay un apoyo político explícito para los vehículos eléctricos, pero la «Ley de Movilidad» del estado pinta a grandes rasgos la importancia de considerar los impactos ambientales, las emisiones y las tecnologías sustentables que podrían justificar los programas de vehículos eléctricos (Instituto de movilidad del estado de Quintana Roo 2019). Según la Secretaría de Energía, el estado y el sector privado están interesados en promover la electromovilidad en Quintana Roo, aunque siguen existiendo varias barreras, como la posible resistencia de los sindicatos del transporte público y la escasez de estaciones de carga disponibles para los vehículos eléctricos privados. El Instituto de Desarrollo Financiero de Quintana Roo ha participado recientemente en una iniciativa liderada por Tesla para promover la electromovilidad mediante la instalación de estaciones de carga.

Conocer los tipos de vehículos registrados en la Península puede orientar la toma de decisiones sobre políticas y programas de vehículos eléctricos. Esta información podría indicar qué sectores de vehículos (por ejemplo, oficial, público, particular) y qué tipo de vehículos (por ejemplo, automóviles, camiones, motos) podrían ser objeto de electrificación. Los responsables de la toma de decisiones tendrán que sopesar muchos factores para determinar dónde dirigirse. Algunos tipos de vehículos o sectores pueden ser más fáciles de electrificar inicialmente que otros.

Además de las recomendaciones generales esbozadas por Shapiro y Campero (2012), los estados de la Península y en particular Quintana Roo podrían considerar medidas adicionales de electrificación del 
transporte que podrían fortificar el desarrollo económico, particularmente el turismo, en la región, incluyendo:

1. Explorar la viabilidad del equipamiento de suministro de vehículos eléctricos públicos a lo largo de los principales corredores que conectan tres ciudades principales de Yucatán para permitir el transporte electrificado de media y larga distancia dentro de la región. El gobierno federal de México ha dado prioridad a los proyectos de infraestructuras de transporte en Yucatán, como demuestran los planes para el Tren Maya, destinado a unir las atracciones turísticas y las comunidades de la región. Los equipos de suministro de vehículos eléctricos y los desplazamientos en vehículos eléctricos podrían desplegarse de forma complementaria a este proyecto de infraestructura.

2. Pilotar la electrificación de determinadas flotas de vehículos, como los autobuses de tránsito, los taxis (especialmente los que prestan servicio en los aeropuertos), los vehículos municipales y las motocicletas. Las flotas suelen ser las primeras en adoptar los vehículos eléctricos debido a sus constantes patrones de desplazamiento y (normalmente) a su capacidad de carga y gestión centralizadas. La electrificación de los autobuses de tránsito a lo largo de las rutas más populares y/o de los taxis o lanzaderas de los hoteles que viajan hacia y desde los aeropuertos a los centros turísticos también eleva el perfil de los vehículos eléctricos entre el público, apoyando una mayor familiaridad con esta nueva tecnología.

\section{Trabajo futuro}

La evaluación proporcionada y el menú de opciones para el posible desarrollo es el primer paso del programa 21CPP México para proporcionar asistencia técnica a los estados de la península de Yucatán. Los estados de la península tienen algunas diferencias únicas, pero comparten muchas áreas comunes. Este trabajo pretende ayudar a los estados a priorizar los próximos pasos y puede incluir algunas de las siguientes actividades:

- Junto con los funcionarios estatales de energía y el CENACE local, el desarrollo de un análisis más profundo, incluyendo un estudio regional de futuros de energía renovable, donde varios escenarios de penetración de las renovables, el suministro de gas y los escenarios de precios, los escenarios de ubicación de las dos plantas de energía propuestas por la CFE, etc., podrían ser modelados para entender su impacto en la seguridad energética, la confiabilidad, los impactos ambientales y los precios.

- Definición y cartografía de las zonas que deben considerarse para el pre-desarrollo de proyectos eólicos y solares a escala de servicios públicos y de DG, basándose en la propiedad de los terrenos, las exclusiones, la capacidad de transmisión en la zona, los impactos ambientales y sociales, etc.

- Desarrollo de capacidades, modelos y herramientas para ser utilizados por los funcionarios estatales de energía.

- En colaboración con los estados y otros donantes de la región, el desarrollo de programas, políticas y modelos empresariales que se ajusten a las prioridades energéticas estatales y regionales.

- Creación de programas piloto como los ejidos solares para la adquisición estatal de energía limpia.

- Análisis de la capacidad de la red de distribución y desarrollo de programas para controlar el impacto de la energía solar fotovoltaica en la red.

- Creación de capacidades y colaboración para realizar auditorías energéticas y proponer soluciones de eficiencia energética y mecanismos de financiamiento.

- Análisis de posibles políticas e incentivos subnacionales para crear programas de transporte sustentable. 


\section{Referencias}

ACEEE. “Topics.” https://www.aceee.org/all-topics.

Aleatica. 2017. «Evento relevante: Lanzamiento del servicio de peaje EcoTAG». 12 de junio de 2017. https://inversionistasmx.aleatica.com/ecotag-toll-service/.

Ayuntamiento de Merida. 2019. Plan Integral de Movilidad Urbana Sustentable. Implan. http://isla.merida.gob.mx/serviciosinternet/ordenamientoterritorial/docs/PIMUS_2040.pdf.

Aznar, Alexandra, Stephane De la Rue du Can, y Alberto Díaz. 2019. USAID Promover la eficiencia energética en los países en desarrollo. Golden, CO: NREL. NREL/TP-7A40-71915. https://www.nrel.gov/docs/fy19osti/71915.pdf.

Banco de Mexico. 2017. Indicadores Básicos de Créditos a las Pequeñas y Medianas Empresas (PYMES). https://www.banxico.org.mx/publicaciones-y-prensa/rib-creditos-apymes/\%7B6F30DAE4-E446-DE94-8A66-84CB2E2E0F54\%7D.pdf.

Baz, Verónica, Luis Serra, Miguel Angel Toro, Ana Lilia Moreno, Jorge Ramírez Mata, Eduardo Reyes, y Gabriela Legorreta. 2015. «Modificar los Subsidios Eléctricos Para Garantizar la Eficiencia del Sector: Es Posible (CIDA, 2015)». Centro de Investigación para el Desarrollo, A.C. (CIDAC). http://cidac.org/esp/uploads/1/subsidios_electricos_29abr.pdf.

Berrera, Adriana. 2021. «ACTUALIZA 3-Suprema Corte México declara procedente controversia contra política electricidad Gobierno». Reuters. 03 de febrero de 2021.

https://www.reuters.com/article/energia-mexico-idMXL1N2K932H.

CFE. «Esquema tarifario vigente». https://app.cfe.mx/Aplicaciones/CCFE/Tarifas/TarifasCRECasa/Casa.aspx.

CONCANACO. 2019. «La Península de Yucatán requiere de gas Natural e infraestructura para el abastecimiento y electricidad a menor costo». 21 de agosto de 2019. https://www.concanaco.com.mx/la-peninsula-de-yucatan-requiere-de-gas-natural-einfraestructura-para-el-abastecimiento-y-electricidad-a-menor-costo-concanaco-servytur/.

Cooperación Alemana y GIZ. 2018. Catálogo de Publicaciones del Programa Energía Sustentable en México, Segunda versión. https://energypedia.info/images/9/95/Cat\%C3\%A1logo_de_publicaciones_del_Programa_Energ $\%$ C3\%ADa_Sustentable_en_M\%C3\%A9xico._Segunda_Versi\%C3\%B3n.pdf.

Cooperación Alemana y GIZ. 2017. Sistematización de estrategias y actividades de eficiencia energética en empresas de agua.

https://energypedia.info/images/9/98/Sistematizacion_EE_Empresas_Agua_GIZ.pdf.

Diario de Yucatán. 2019. «Incentivo para los comercios: Se busca detonar el uso de energía "verde" en Mérida». 17 de octubre de 2019. https://www.yucatan.com.mx/merida/se-busca-detonar-el-usode- energía-verde-en-merida.

Energía a Debate. 2020. «Anuncian Gasoducto Cuxtal-Mayakán de ENGIE». https:/www.energiaadebate.com/gas-natural/anuncian-gasoducto-cuxtal-mayakan-de-engie/. 
Estado de Yucatán (Gobierno del Estado de Yucatán). 2021. «Para proteger los empleos de los yucatecos, el Gobernador Mauricio Vila Dosal y Banverde firman convenio para que empresas puedan acceder a financiamiento y adquirir paneles solares para reducir costos de energía eléctrica». Comunicado de prensa. 19 de febrero de 2021 https://www.yucatan.gob.mx/saladeprensa/ver_nota.php?id=4278.

Gerencia de Energías Renovables del Instituto Nacional de Electricidad y Energías Limpias (INEEL) e Iniciativa Climática de México, A.C. (ICM). 2019. «Financiamiento para Acceder a Tecnologías de Energías Renovables de Generación Eléctrica Distribuida (FATERGED) en México: Estudio de mercado de tecnología solar fotovoltaica distribuida para MiPyMEs», Versión 1.0. Marzo de 2019.

Instituto de movilidad del estado de quintana roo. 2019. Ley de Movilidad Del Estado de Quintana Roo. http://documentos.congresoqroo.gob.mx/leyes/L189-XV-16012019-787.pdf.

McNeil, Michael, Jeffrey Logan, Douglas Gagne, y Emily Chen. 2020. USAID Aumento de la eficiencia energética en los países en desarrollo. Golden, CO: Laboratorio Nacional de Energías Renovables. https://ee4d.org/wp-content/uploads/sites/40/2020/11/USAID_EE4D_EnergyEfficiency_Building-Blocks_Toolkit_508.pdf.

MIM (Monitor Independiente de Mercado). 2019. Reporte Anual del Mercado Eléctrico Mayorista 2019. https:/www.gob.mx/cms/uploads/attachment/file/553784/Reporte_Anual_2019_del_Monitor_Ind ependiente_del_Mercado.pdf.

NREL. «Análisis de la Zona de Energías Renovables de México - Imagen web GIS». https://tinyurl.com/y86eeh3t.

RIC Energy. 2020. «Generación Distribuida en México, ¿Cómo Vamos?». https:/www.ric.mx/cultura/energia/generacion-distribuida-en-mexico.

Secretaria de Hacienda y Crédito Público. 2014. Ley de Ingresos de La Federación Para El Ejercicio Fiscal de 2015. http://www.hacienda.gob.mx/INGRESOS/Ingresos_ley/2015/lif_2015.pdf.

Shapiro, Charles S., y Alexandra Noreiga Campero. 2012. Vehículos eléctricos en México: una opción económica ecológica para las flotas. Institute for the Americas.

https://www.iamericas.org/documents/vehiculos_electricos_mexico_web.pdf.

Secretaría de Gobierno. 2020. Decreto por el que se modifica la Tarifa de la Ley de los Impuestos Generales de Importación y Exportación.

https://www.dof.gob.mx/nota_detalle.php?codigo=5599614\&fecha=03/09/2020.

Solís, Arturo. 2019. «La administración de AMLO gastará 70,000 mdp en subsidios a la luz». Forbes México. 10 de septiembre. https://www.forbes.com.mx/gobierno-de-amlo-gastara-70000-mdp-ensubsidiar-la-luz.

Tellez Martine, Jose Antonio, y Karime Vazquez. 2018. «Vehículos eléctricos en México | Desarrollos que impactan en la industria de los vehículos eléctricos». CMS Legal.

https://cms.law/en/int/expert-guides/cms-expert- guide-to-electric-vehicles/mexico.

USAID. 2020. AUMENTO DE LA EFICIENCIA ENERGÉTICA EN LOS PAÍSES EN DESARROLLO. Washington, D.C.: USAID. https://ee4d.org/wp- 
content/uploads/sites/40/2020/11/USAID_EE4D_Energy-Efficiency_BuildingBlocks_Toolkit_508.pdf.

Villarreal y Pavlovic, entrevista telefónica. 2020 


\section{Anexo A: Mejores prácticas y soluciones de eficiencia energética por tipo de sistema}

Las diferentes industrias y zonas económicas de la región tienen un papel fundamental en la adopción y el despliegue de medidas de eficiencia energética. La adopción de estas medidas redundará no sólo en el importante objetivo de obtener ahorros energéticos y, por tanto, de mejorar su posición competitiva, sino que, más allá de eso, resonará en muchos aspectos sociales que devolverán la calidad de vida a las comunidades de los estados del sur de México, especialmente bajo el nuevo contexto de pandemia. A continuación, se enumeran una serie de posibles medidas de ahorro energético útiles para los estados de la península para obtener el mayor impacto.

\section{Subestaciones eléctricas y distribución eléctrica}

1. Redistribución de cargas en transformadores. Consiste en evitar el funcionamiento de transformadores sobrecargados o con poca carga, distribuyendo las cargas conectadas a ellos.

2. Corregir el desequilibrio de fase. Consiste en evitar que los equipos eléctricos trifásicos se alimenten con un valor de tensión diferente en cada una de las tres fases.

3. Regulación de la tensión de alimentación. Esto es para evitar que la tensión varíe demasiado dentro de la empresa.

4. Instalación de baterías de condensadores en subestaciones. La batería de condensadores es un accesorio utilizado para mejorar el factor de potencia de una empresa; el contexto se refiere a cuando se instala en la recepción de energía eléctrica para toda la empresa.

5. Instalación de baterías de condensadores en equipos privados.

\section{Sistemas de aire comprimido}

1. Instalar motores de alta eficiencia en los compresores.

2. Sustituir los compresores por otros de tecnología de ahorro de energía. Consiste en cambiar los compresores por otros que consuman menos energía.

3. Reducir o eliminar fugas. Se trata de reducir o evitar el aire comprimido que se escapa sin ser utilizado en tuberías, accesorios y equipos.

4. Automatizar el funcionamiento de los compresores. Se refiere a la instalación de equipos para regular automáticamente el funcionamiento del compresor.

5. Adaptar la capacidad del sistema a las necesidades reales de aire comprimido. Consiste en corregir el sistema de aire comprimido haciendo que su capacidad se corresponda con las necesidades del sistema.

6. Instalar tanques de almacenamiento. Consiste en la instalación de un depósito para almacenar el aire comprimido, reduciendo así los tiempos de carga del compresor.

7. Modificar el sistema de distribución con criterios de ahorro. Consiste en realizar cambios para reducir las pérdidas en el sistema de aire comprimido.

8. Modificar tuberías.

9. Reducir la ruta de distribución.

10. Reducir válvulas y accesorios.

11. Instalar accionamientos de velocidad variable (frecuencia) y variadores electrónicos de velocidad. 


\section{Sistemas de bombeo}

1. Instalar motores eléctricos de alta eficiencia en las bombas.

2. Adecuar la potencia del motor a la carga impulsada por la bomba. Esto se refiere a las bombas que tienen un motor eléctrico de potencia eléctrica adecuada.

3. Sustituir las bombas actuales por otras que funcionen de forma más eficiente. Consiste en cambiar las bombas por otras que consuman menos energía.

4. Reducir o eliminar fugas. Se trata de reducir o evitar los líquidos que se escurren sin ser utilizados en tuberías, accesorios y equipos.

5. Automatizar el funcionamiento del sistema de bombeo.

6. Adaptar la capacidad del sistema a las necesidades reales de bombeo.

7. Modificar el sistema de distribución con criterios de ahorro.

8. Instalar variadores de velocidad electrónicos.

\section{Refrigeración}

1. Instalar motores de alta eficiencia en los compresores.

2. Instalar motores de alta eficiencia en las bombas de agua fría y de retorno.

3. Instalar motores de alta eficiencia en los ventiladores de las torres de refrigeración.

4. Sustituir los compresores por otros de mayor eficiencia.

5. Instalar sistemas de almacenamiento térmico, como bancos de hielo.

6. Comprobar la adecuación de la potencia del motor a la carga accionada por los compresores.

7. Automatizar el sistema de control, eliminando los compresores innecesarios.

8. Limpiar los evaporadores y condensadores.

9. Instalar o corregir el aislamiento térmico de conductos, cilindros o tuberías.

10. Aislar tanques, cámaras frigoríficas, bancos de hielo y otros equipos.

11. Instalar cortinas aislantes en las puertas de entrada a las cámaras frigoríficas.

12. Controlar la circulación del aire sobre el producto almacenado.

13. Enfriar previamente el agua o el aire.

14. Instalar variadores de velocidad electrónicos en compresores, ventiladores y bombas.

\section{Equipo de aire acondicionado}

1. Instalar motores de alta eficiencia en los compresores.

2. Instalar motores de alta eficiencia en las bombas de agua fría.

3. Instalar motores de alta eficiencia en los manipuladores de aire.

4. Sustituir los compresores por otra tecnología de ahorro de energía. Consiste en cambiar los compresores por otros que consuman menos energía, por ejemplo, los de tornillo alternativo o los centrífugos.

5. Instalar un sistema de almacenamiento térmico, como bancos de hielo. Consiste en almacenar el frío en tanques o almacenes y aprovecharlo para reducir la demanda de energía en los momentos críticos o más caros. 
6. Garantizar la adecuación de la potencia del motor a la carga accionada por los compresores. Esto se refiere a los compresores que tienen un motor eléctrico de potencia eléctrica adecuada.

7. Automatizar el sistema de control, eliminando los compresores innecesarios. Se trata de reducir el número de compresores en funcionamiento, evitando que los compresores trabajen innecesariamente, incluso por períodos.

8. Limpiar los evaporadores y condensadores. Consiste en realizar una limpieza sistemática de los evaporadores y condensadores del sistema de refrigeración para eliminar las incrustaciones.

9. Instalar aislamiento térmico en paredes y techos. Se trata de aislar térmicamente las paredes y los techos del edificio acondicionado.

10. Mantener el aislamiento térmico de los conductos o tuberías. Se trata de mantener en perfecto estado el aislamiento térmico de los distintos componentes que accionan el aire acondicionado.

11. Aplique una película reflectante en las ventanas para reducir la entrada de calor. Se trata de

12. Colocar una lámina que rechace la radiación solar que incide sobre las ventanas.

13. Enfriar previamente el agua o el aire. Consiste en realizar el proceso de enfriamiento en dos o más etapas, evitando así grandes diferencias entre la temperatura inicial del aire o del agua y la que debe alcanzar.

14. Instalar variadores de velocidad electrónicos en compresores, unidades de tratamiento de aire y bombas. Consiste en la instalación de un equipo de control electrónico denominado «convertidor de frecuencia variable o variador electrónico de velocidad», que controla la velocidad del motor eléctrico de este equipo.

\section{Sistemas de iluminación}

1. Instalación de compuertas individuales para controlar las zonas. Consiste en colocar interruptores en los despachos, las aulas, los auditorios y todas las zonas en las que se pueda apagar la iluminación de forma individual.

2. Sustituir las bombillas incandescentes por LEDs.

3. Sustituir las lámparas fluorescentes por otras lineales (T-8) de mayor eficiencia. Consiste en cambiar las lámparas fluorescentes convencionales por otras que, con menos potencia eléctrica, dan igual o más luz.

4. Sustituir las lámparas de vapor de mercurio por lámparas de sodio de alta presión.

5. Sustituir las lámparas de vapor de mercurio por aditivos metálicos.

6. Instalar reflectores especulares, reduciendo el número de lámparas. Consiste en reducir el número de tubos fluorescentes por luminaria añadiendo un reflector de aluminio especular que refleja la luz que incide sobre él.

7. Sustituir los balastos convencionales por balastos de bajo consumo. Consiste en sustituir el balasto de los sistemas de iluminación por otro que consuma menos energía.

8. Instalar sensores de presencia. Estos encienden la luz cuando detectan la presencia humana y apagan las luces cuando la zona está desocupada.

9. Instalar reductores de intensidad (reguladores) para las lámparas. Este equipo se utiliza para reducir la intensidad luminosa de algunas lámparas, reduciendo al mismo tiempo la energía consumida.

10. Instale fotocélulas para apagar la iluminación en las zonas que reciben buena luz natural. 
11. Instalar láminas o cúpulas translúcidas. Estas láminas permiten el paso de la luz natural, lo que permite a los ocupantes apagar las luces interiores.

12. Aplicar controles de apagado programados en función de los horarios o de la política de la empresa. Se trata de medidas de apagado o encendido de luces por horarios o cuando se deja la zona sin personal trabajando.

13. Instalar un sistema de control de la iluminación general. Se trata de un equipo informatizado que permite a los ocupantes apagar las luces por horario, presencia, luz natural y teléfono, entre otros.

\section{Procesos de producción}

1. Sustituir las resistencias eléctricas por la tecnología de infrarrojos. La tecnología de infrarrojos consiste en un calentamiento basado en la radiación infrarroja, emitida por tubos de cuarzo o equipos similares.

2. Sustituya las resistencias eléctricas por un combustible como el gas licuado del petróleo, el gas natural, el diésel u otro. Consiste en cambiar los procesos de calefacción que utilizan resistencias por otros que utilizan gas licuado del petróleo, gas natural, diésel u otros como fuente de energía.

3. Sustituir los motores estándar por los de alta eficiencia. 


\section{Anexo B: Panorama de la generación de energía en México}

Mientras los estados de la Península de Yucatán sopesan sus opciones de energía sustentable, la capacidad de generación de energía y la producción anual de todo México pueden ofrecer una perspectiva valiosa. Para una flota de centrales eléctricas, la capacidad se designa por la suma de los valores nominales que representan la cantidad máxima a corto plazo (por hora) que una determinada central puede producir electricidad, limitada por restricciones medioambientales o de funcionamiento. Como se ilustra en para los años 2014 a 2018, los combustibles fósiles y las energías renovables constituyen la base de casi toda la capacidad de generación eléctrica en México, apoyada también por una pequeña cantidad de capacidad nuclear. La figura B-2 proporciona una granularidad de la capacidad de generación de energía renovable para el país durante el mismo periodo de tiempo.

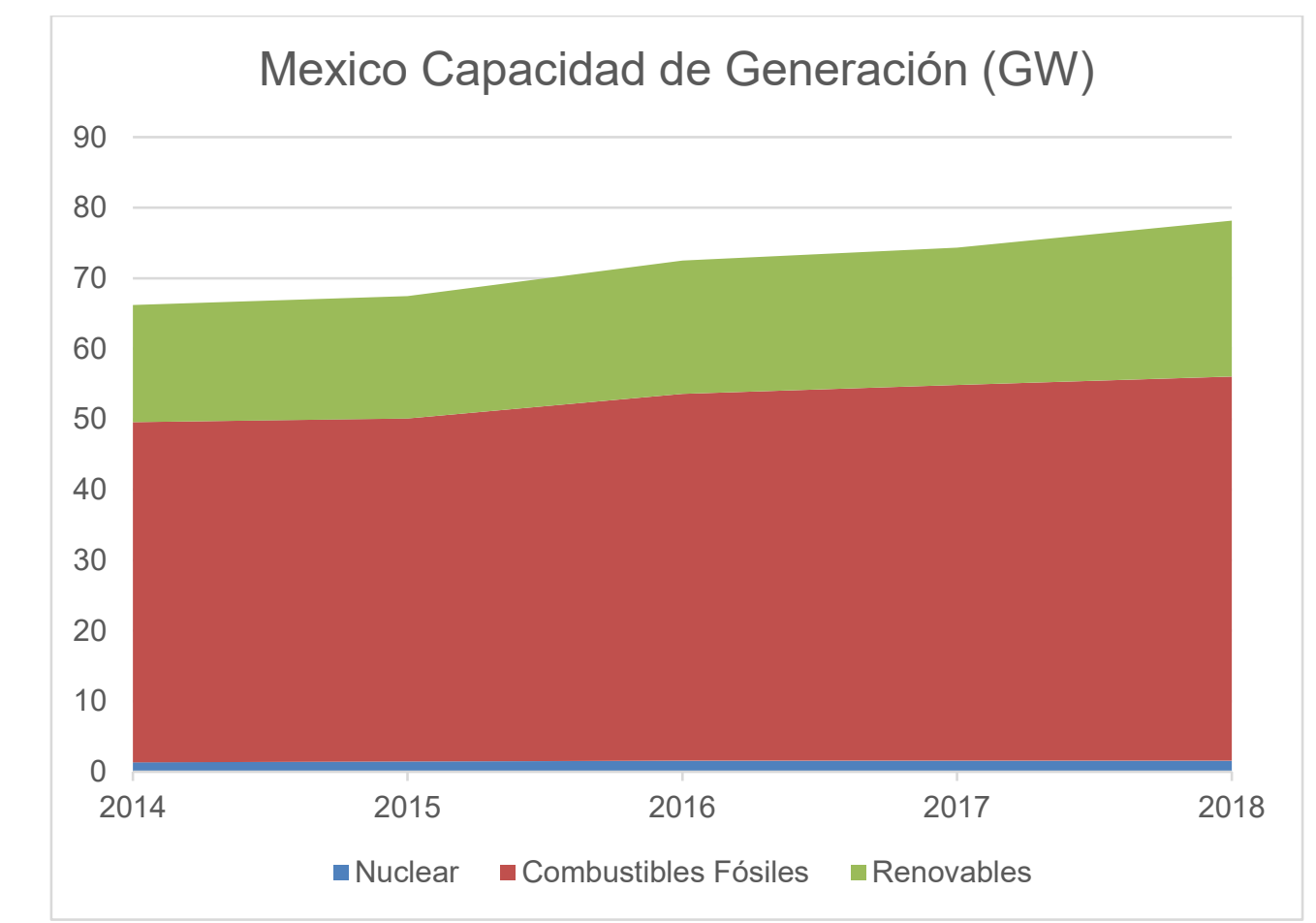

Figura B-1. Capacidad anual de generación de energía limpia en México frente a la de combustibles fósiles

Fuente: CFE vía EIA 


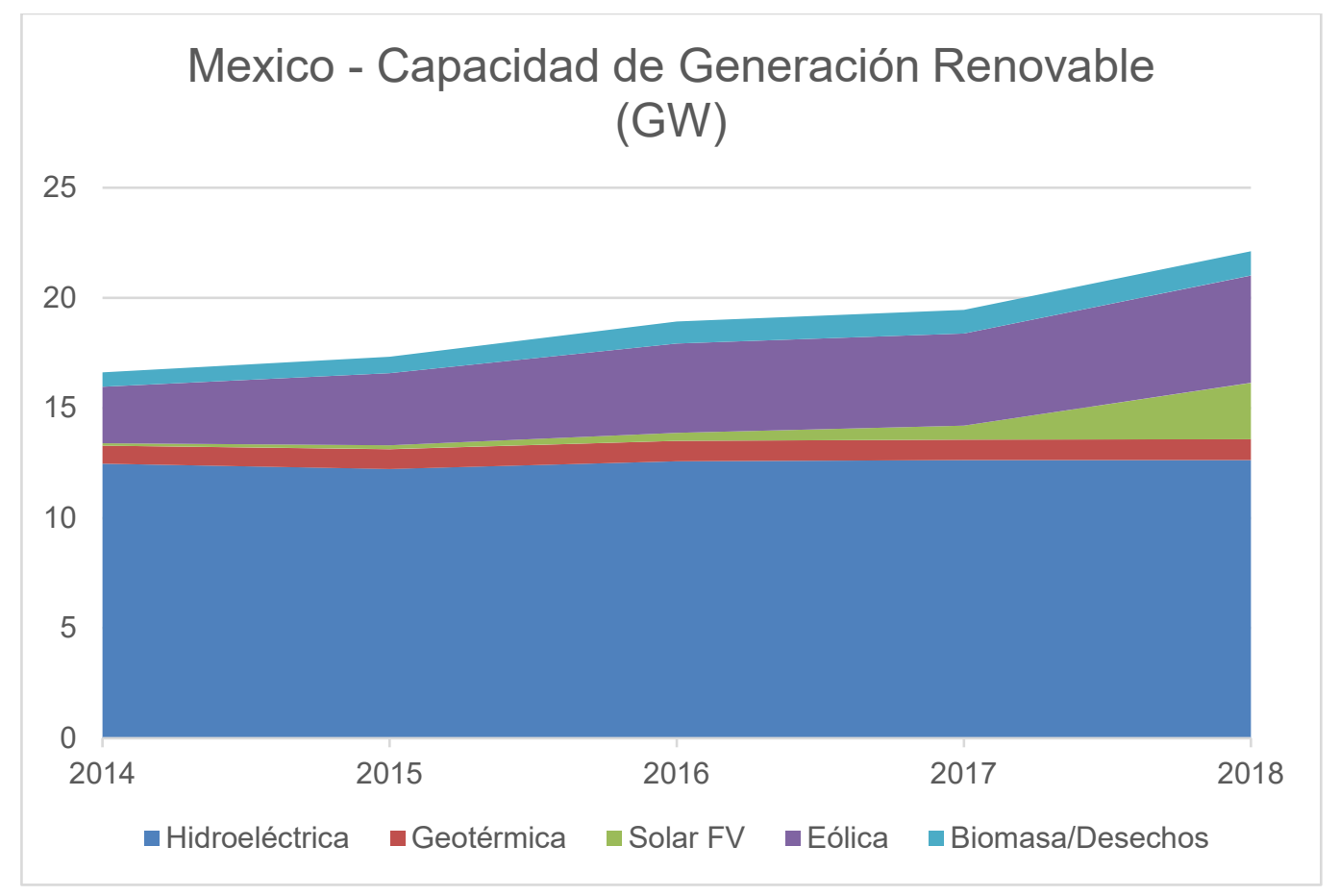

Figura B-2. Desglose de la capacidad de generación renovable anual de México

Fuente: CFE vía EIA

Como muestra la, la energía hidroeléctrica representa casi el $60 \%$ de la capacidad eléctrica renovable de México. Sin embargo, el crecimiento de la energía hidroeléctrica y la geotérmica ha sido modesto durante el periodo de tiempo indicado, mientras que la biomasa y la eólica casi han duplicado su capacidad, y la capacidad solar fotovoltaica era más de 22 veces mayor en 2018 que en 2014.

Mientras que la capacidad refleja la capacidad a corto plazo de una central eléctrica, la generación representa la producción real a largo plazo de la central. La Figura B-3 ilustra la producción anual real de energía para México desde 2014 hasta 2018. Del crecimiento de la generación de energía que se produjo durante este periodo ( $30 \mathrm{TWh}$ ), más del $80 \%$ de ese crecimiento procedió de los combustibles fósiles, y el resto del crecimiento se repartió casi por igual entre la energía nuclear y las renovables. La Figura B-4 proporciona la granularidad de la producción de electricidad renovable desde 2014 hasta 2018. 


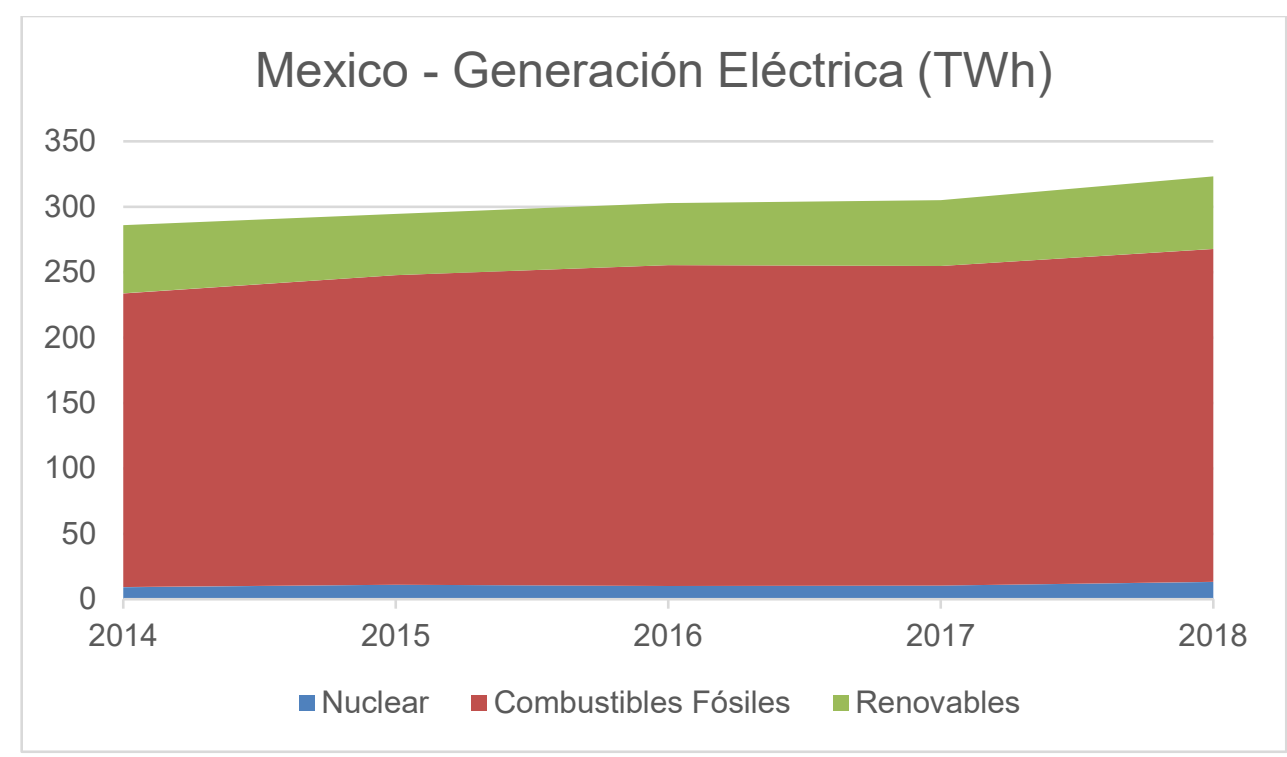

Figura B-3. La generación anual de energía limpia en México frente a la generación basada en combustibles fósiles

Fuente: CFE vía EIA

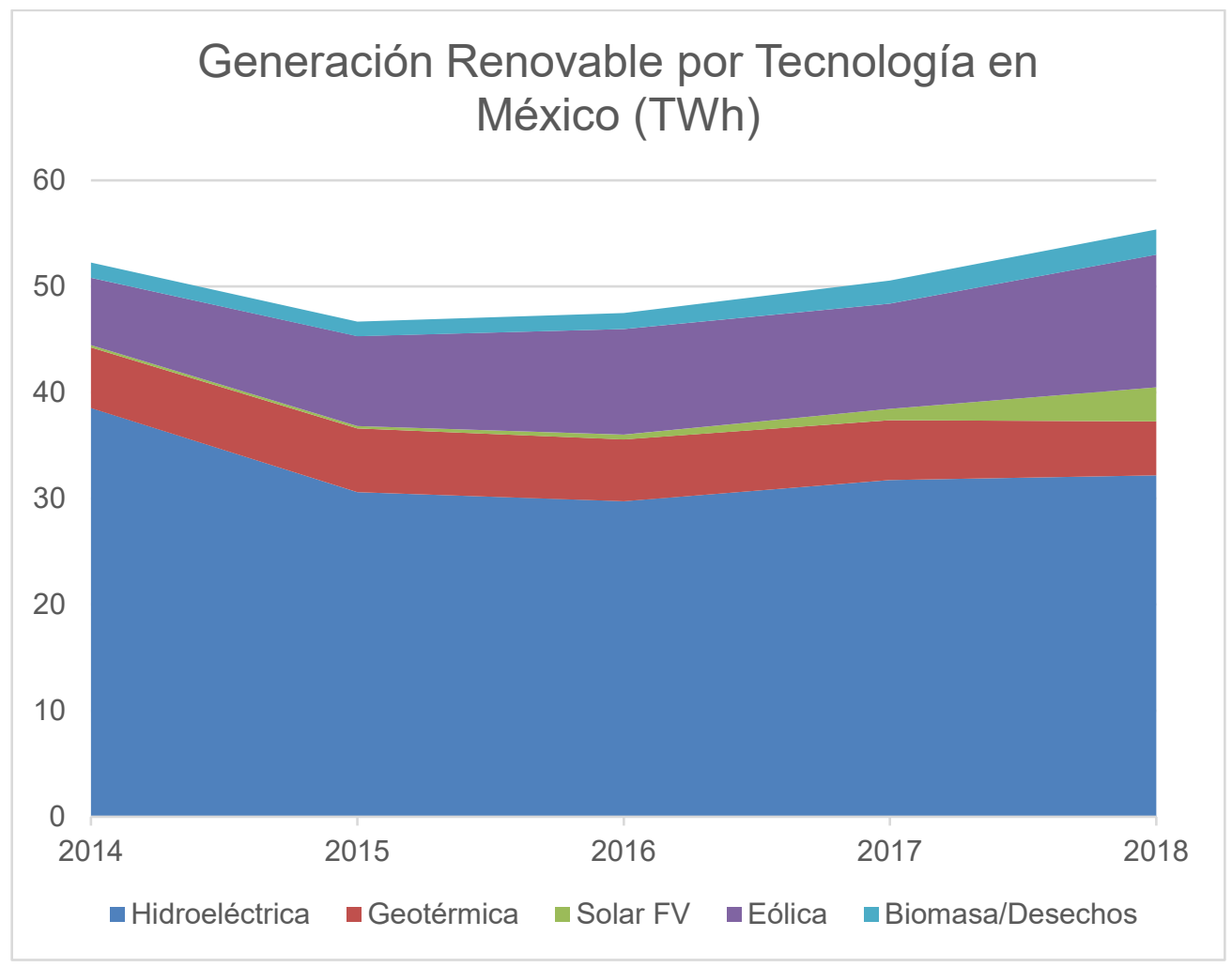

Figura B-4. Desglose de la generación anual de energía renovable en México

Fuente: CFE vía EIA

Como ilustra la Figura B-4, la producción de electricidad a partir de energía hidroeléctrica y geotérmica disminuyó en casi 7 TWh en todo México. El declive de la generación hidroeléctrica se debe sobre todo a los años de sequía y a la creciente necesidad de utilizar el agua aparte de la generación de energía. La producción eólica, solar y de biomasa aumentó en más de 10 TWh, sobre todo la eólica. 
El factor de capacidad es otro concepto importante a la hora de revisar las opciones energéticas para la Península de Yucatán. El factor de capacidad, expresado en forma de porcentaje, se calcula dividiendo la producción anual real de una central eléctrica por la producción anual teórica de dicha central, suponiendo que ésta pudiera funcionar a pleno rendimiento durante todas las horas del año. ${ }^{13} \mathrm{Si}$ bien estos cálculos son más relevantes para una central eléctrica individual, podemos determinar un factor de capacidad aparente para el sector de generación de electricidad de México y para cada tecnología de la cartera. La figura B-5 muestra el factor de capacidad aparente de las energías fósiles, renovables y nucleares.

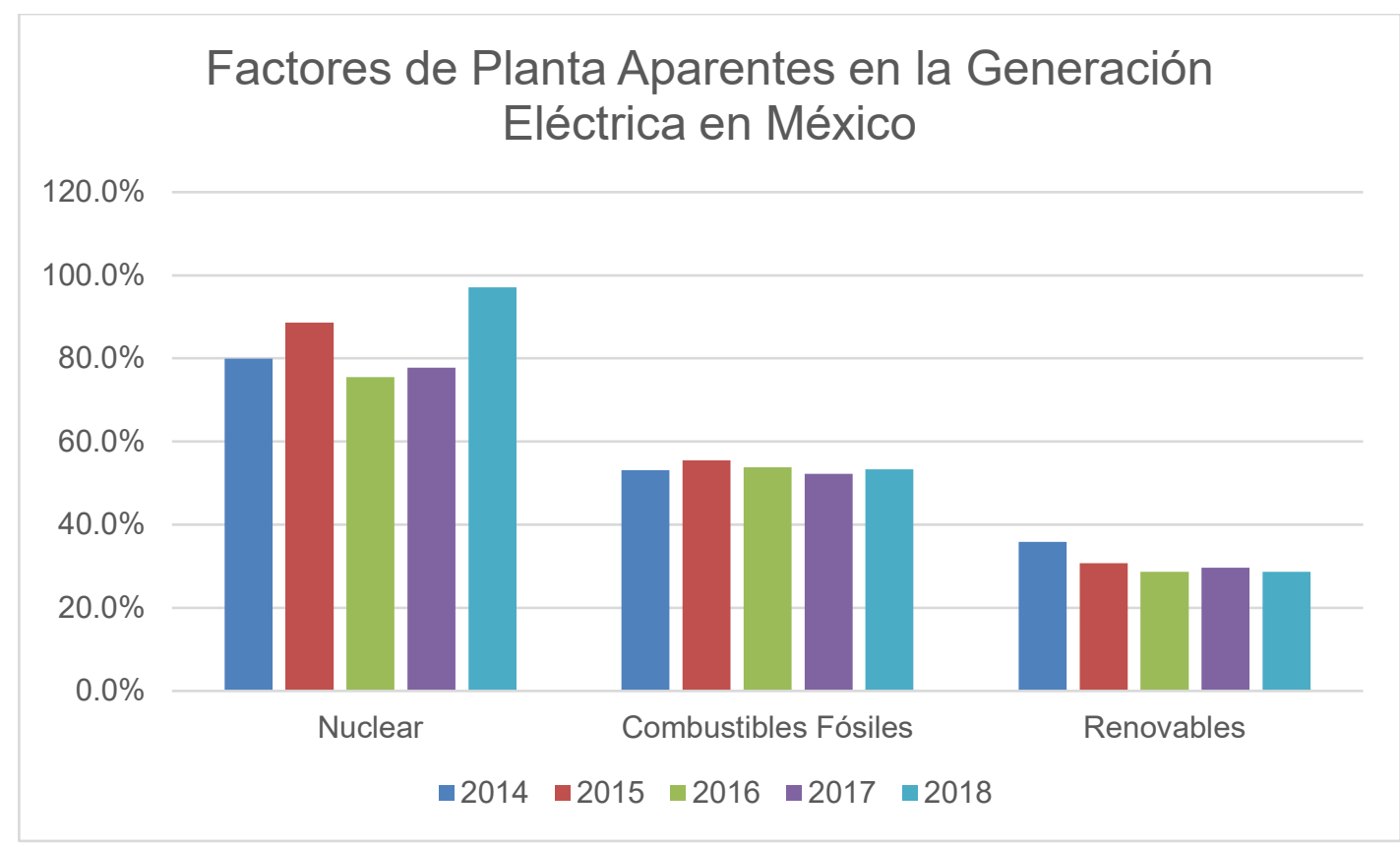

Figura B-5. Factor de capacidad de generación eléctrica anual de México: energías limpias frente a combustibles fósiles

Fuente: CFE vía EIA

La Figura B-5 muestra que, en 2018, el parque nuclear de México operaba al 97\% de la capacidad, la generación fósil es el 53\% de la capacidad y las alternativas renovables son el $29 \%$ de la capacidad. La Figura B-6 proporciona una granularidad adicional para la flota renovable de México.

\footnotetext{
${ }^{13}$ Factor de capacidad $=($ Producción real $/($ Capacidad nominal x 8760) $) \times 100 \%$.
} 


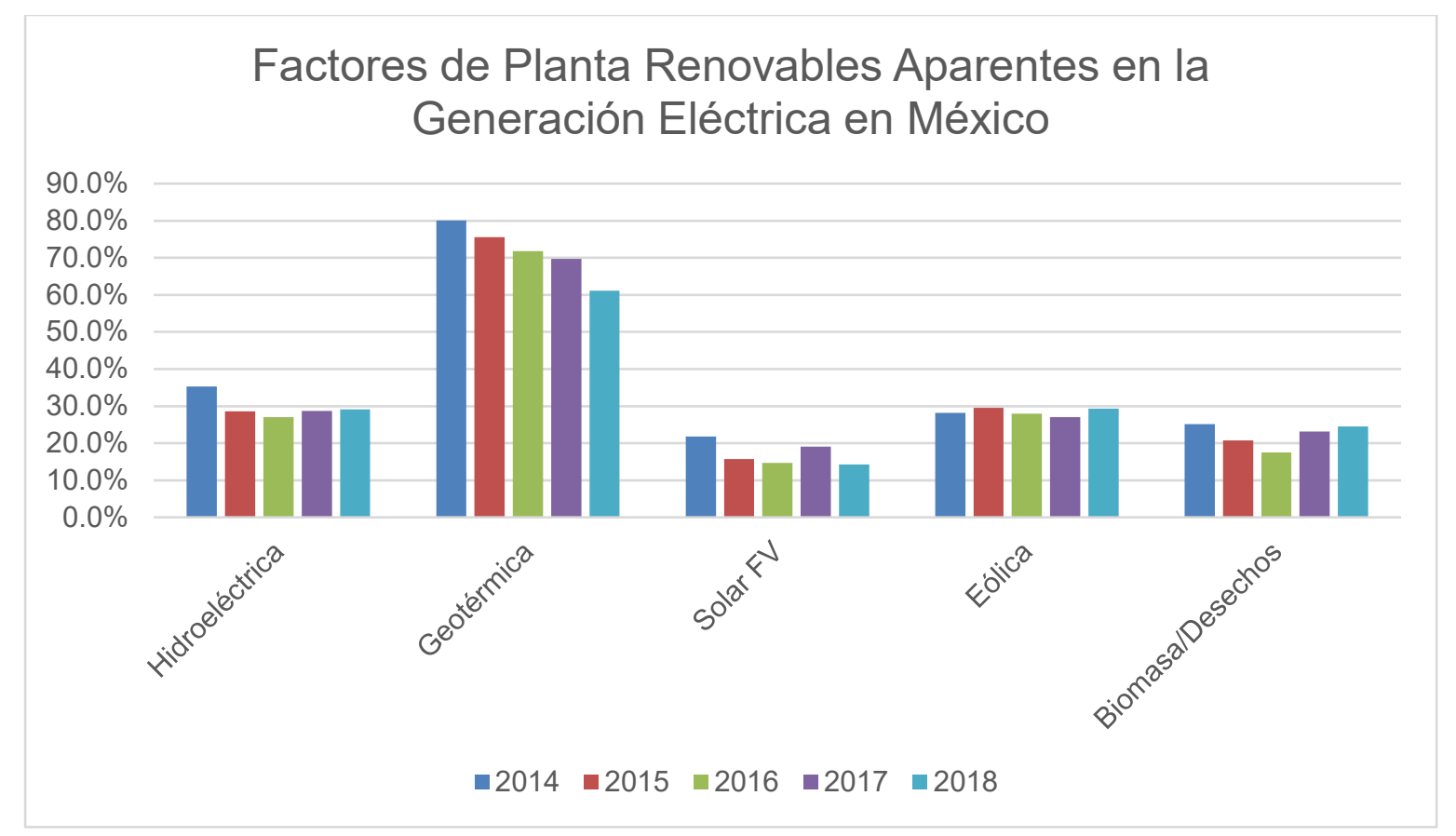

Figura B-6. Factores de capacidad estimados en México por tecnología renovable Fuente: CFE vía EIA

Los factores de capacidad aparente presentados en la Figura B-6 demuestran la naturaleza intermitente de varias opciones de energía renovable. Las centrales geotérmicas suelen tener la menor variabilidad porque el recurso geotérmico del subsuelo es constante durante todo el año. La energía hidráulica puede ser variable, en función de las precipitaciones, los usos del agua en competencia y otros factores. La bioenergía suele estar ligada a las temporadas de cultivo. La energía eólica y la energía solar dependen de que el viento sople y el sol brille.

Los factores de capacidad aparente determinados para las distintas flotas de tecnología de generación a partir de datos empíricos ofrecen una visión útil, aunque imperfecta, para una central eléctrica individual contemplada. Por ejemplo, a partir de los datos de la Figura B-6, se esperaría que un proyecto de energía eólica en México produjera a un factor de capacidad nominal del 30\% en el transcurso de un año, reconociendo que la producción variará diurna y estacionalmente.

Aunque los factores de capacidad aparente pueden ser útiles, existen limitaciones. En primer lugar, el rendimiento pasado de los proyectos existentes puede no ser confiable en última instancia para una nueva central eléctrica individual, sobre todo si la nueva central no está bien diseñada o el recurso es de menor calidad. En segundo lugar, en un mercado relativamente pequeño y en crecimiento, los datos de capacidad incluirán las nuevas centrales eléctricas que se instalen a lo largo del año y que estén en proceso de aumentar su capacidad. Por lo tanto, el factor de capacidad estará sesgado a la baja porque la producción teórica se calculará como si las nuevas centrales eléctricas estuvieran disponibles durante todo el año. Los datos de 2014 a 2018 sugieren que este es el caso tanto de la eólica como de la solar.

\section{Confiabilidad con una mayor penetración de las tecnologías renovables variables}

La lista de tecnologías de energía limpia de la ley mexicana incluye varias que no son renovables, por ejemplo la nuclear y la cogeneración eficiente. Sin embargo, la función principal del sector eléctrico es proporcionar servicio eléctrico de manera confiable y asequible a todos los clientes. Además de las 
interrupciones programadas y no programadas de los generadores, la red debe responder a los cambios en la carga, así como a la variabilidad de la generación dependiente de recursos (como la eólica y la solar). La variabilidad que puede predecirse con un alto grado de confianza se aborda a través de la programación de energía planificada, como los mercados diarios y la planificación de recursos plurianuales. La variabilidad a corto plazo y menos predecible se aborda en el mercado en tiempo real y con servicios auxiliares como los que proporciona la generación de respuesta rápida (turbinas de gas y motores diésel). La confiabilidad del sistema aumenta al acortar el tiempo de despacho del sistema.

La energía solar y eólica contribuyen a la variabilidad a corto y largo plazo. Esta variabilidad se gestiona en función del nivel de penetración, pero, en general, el sistema funciona de la misma manera. Las herramientas que proporcionan una mayor flexibilidad al sistema sirven para gestionar la variabilidad adicional que aporta la generación solar y eólica. Por término medio, es poco probable que una generación solar y eólica del 5\% al 10\% afecte a los tipos y la magnitud de las reservas necesarias para gestionar de forma confiable el sistema. En los sistemas reales, se ha observado que cuando se alcanza el $30 \%$ de generación eólica y solar, la magnitud y el momento de las reservas, incluyendo la duración, la estacionalidad y el tiempo de respuesta, pueden requerir algunos ajustes. Es esencial una cuidadosa planificación y diseño de las operaciones en torno a una mezcla diversa de recursos.

La Tabla B-1 aborda seis tecnologías clave de energías renovables y consideraciones generales para su despliegue o expansión en la Península.

Tabla B-1. Consideraciones generales para el despliegue de tecnologías renovables en la Península

\begin{tabular}{|c|c|}
\hline Consideraciones & tecnológicas \\
\hline Energía eólica & $\begin{array}{l}\text { Con más de } 240 \mathrm{MW} \text { de aerogeneradores instalados y otros más en diversas fases de } \\
\text { desarrollo, la Península cuenta con un fuerte recurso eólico que se espera que ocupe un lugar } \\
\text { destacado en la planificación energética. La energía eólica distribuida a pequeña y mediana } \\
\text { escala también puede ser viable. }\end{array}$ \\
\hline $\begin{array}{l}\text { Energía solar } \\
\text { fotovoltaica }\end{array}$ & $\begin{array}{l}\text { En pocos años, la energía solar fotovoltaica ha crecido de forma significativa, lo que demuestra } \\
\text { que la Península cuenta con un sólido recurso solar para la planificación energética, a escala de } \\
\text { servicios públicos y distribuida. Otras formas de energía solar no se consideran } \\
\text { económicamente competitivas en un futuro próximo. }\end{array}$ \\
\hline Energía oceánica & $\begin{array}{l}\text { La energía oceánica sigue en estado de desarrollo y no se espera que sea una oportunidad } \\
\text { cercana para la Península. Puede ser una tecnología que valga la pena considerar a largo } \\
\text { plazo. }\end{array}$ \\
\hline $\begin{array}{l}\text { Energía } \\
\text { geotérmica }\end{array}$ & $\begin{array}{l}\text { Aunque México cuenta con un importante recurso geotérmico, se prevé que el recurso } \\
\text { desarrollable actual en la Península sea limitado. }\end{array}$ \\
\hline Bioenergía & $\begin{array}{l}\text { La bioenergía es una categoría que incluye varias formas de biomasa y de conversión de } \\
\text { residuos en energía. Los recortes forestales, los residuos de las cosechas, los desechos del } \\
\text { ganado, los residuos alimentarios, las algas marinas y otros pueden producir energía mediante } \\
\text { la combustión directa, la digestión anaeróbica, la gasificación, la fermentación y otros métodos. } \\
\text { Aunque el despliegue actual para la generación de energía es limitado, se espera que la } \\
\text { bioenergía ocupe un lugar destacado en la planificación energética de la Península, a escala de } \\
\text { servicios públicos y distribuida. }\end{array}$ \\
\hline $\begin{array}{l}\text { Energía } \\
\text { hidroeléctrica }\end{array}$ & $\begin{array}{l}\text { La Península es plana, con aguas superficiales limitadas. Por lo general, la energía } \\
\text { hidroeléctrica requiere importantes diferencias de altitud. Aunque puede haber oportunidades } \\
\text { para la energía hidroeléctrica de baja altura (baja diferencia de altitud), la energía hidroeléctrica } \\
\text { distribuida a pequeña escala y la energía hidroeléctrica de almacenamiento por bombeo, no se } \\
\text { espera que figure de forma prominente en la combinación energética de la Península como lo } \\
\text { hace en México. }\end{array}$ \\
\hline
\end{tabular}


Para hacer frente a la variabilidad de la eólica y la solar, los operadores del sistema deben conocer y aprovechar la flexibilidad disponible en el sistema eléctrico. Los operadores del sistema también deben aplicar prácticas operativas y nuevas tecnologías para permitir la integración de mayores porcentajes de tecnologías de generación variable. Algunos de los cambios que un operador de sistemas puede añadir son la adopción de sistemas de previsión eólica y solar, el acercamiento a los mercados de electricidad en tiempo real, la incorporación de programas de respuesta a la demanda, la aplicación de mecanismos para compensar a los generadores de combustibles fósiles por su mayor capacidad de rampa, y otros.

El almacenamiento de energía, como las baterías a gran escala o la energía hidroeléctrica de bombeo, son tecnologías que pueden servir de apoyo a las energías renovables para suministrar electricidad despachable. Como recurso autónomo que intenta igualar a una turbina de gas de $100 \mathrm{MW}$, un parque solar tendría que tener un tamaño superior a $500 \mathrm{MW}$ y necesitaría varios días de capacidad de almacenamiento de energía para adaptarse a las condiciones nocturnas y nubladas. El costo de capital de un proyecto solar de este diseño podría ser un orden de magnitud mayor que el de un proyecto comparable de turbina de gas, reconociendo que los costos de operación (combustible) serían considerablemente mayores para el proyecto de turbina de gas. En realidad, el funcionamiento confiable de la oferta y la demanda de electricidad tiene en cuenta todo el sistema y las centrales renovables no se despachan como generadores autónomos. Así, se pueden integrar grandes cantidades de energía renovable en el sistema eléctrico de forma segura. El factor de capacidad y los problemas de almacenamiento de energía ponen de relieve la necesidad de un sólido ejercicio de planificación y diseño, combinado con las mejores prácticas operativas para satisfacer las necesidades de energía sustentable en todo momento y a precios asequibles. 